University of Wollongong

Research Online

Faculty of Engineering and Information

Faculty of Engineering and Information

Sciences - Papers: Part B

Sciences

2020

Thermal conductivity enhancement of nanofluid by adding multiwalled carbon nanotubes: Characterization and numerical modeling patterns

Congcong Du

Quyen Nguyen

Omid Malekahmadi

Ali Mardani

Zahra Jokar

See next page for additional authors

Follow this and additional works at: https://ro.uow.edu.au/eispapers1

Part of the Engineering Commons, and the Science and Technology Studies Commons

Research Online is the open access institutional repository for the University of Wollongong. For further information contact the UOW Library: research-pubs@uow.edu.au 


\title{
Thermal conductivity enhancement of nanofluid by adding multiwalled carbon nanotubes: Characterization and numerical modeling patterns
}

\author{
Abstract \\ (C) 2020 John Wiley \& Sons, Ltd. Nanofluid is divided in two major section, mono nanofluid (MN) and \\ hybrid nanofluid (HN). MN is created when a solid nanoparticle disperses in a fluid, whereas $\mathrm{HN}$ has more \\ than one solid nanomaterial. In this research, iron (III) oxide (Fe3O4) is $\mathrm{MN}$, and Fe304 plus multiwalled \\ carbon nanotube (MWCNT) is HN, whereas both are mixed and dispersed into the water basefluid. \\ Thermal conductivity (TC) of Fe304/water and MWCNT/Fe304/water was measured after preparation \\ and numerical model performed on the resulted data. After that, field emission scanning electron \\ microscope (FESEM) was studied for microstructural observation of nanoparticles. MN and HN TC were \\ studied at temperature ranges of 25 to $50^{\circ} \mathrm{C}$ and volume fractions of $0.2 \%$ to $1.0 \%$. For $\mathrm{MN}$ and $\mathrm{HN}$, \\ thermal conductivity enhancement (TCE) of $32.76 \%$ and $33.23 \%$ was measured at $50^{\circ} \mathrm{C}$ \\ temperature $-1.0 \%$ volume fraction, individually. Different correlations have been calculated for numerical \\ modeling, with R2 $=0.9$. Deviation of $0.6007 \%$ and $0.6096 \%$ was calculated for given correlations for $\mathrm{MN}$ \\ and $\mathrm{HN}$ individually. Deviation of $0.5862 \%$ and $0.6057 \%$ was calculated for trained models, for $\mathrm{MN}$ and $\mathrm{HN}$ \\ individually. Thus, by adding MWCNT to Fe $304-\mathrm{H} 2 \mathrm{O}$ nanofluid, TC is enhanced $0.47 \%$, and this $\mathrm{HN}$ has \\ agreeable heat transfer potential.

\section{Disciplines} \\ Engineering | Science and Technology Studies

\section{Publication Details} \\ Du, C., Nguyen, Q., Malekahmadi, O., Mardani, A., Jokar, Z., Babadi, E., D'Orazio, A., Karimipour, A., Li, Z. \& \\ Bach, Q. (2020). Thermal conductivity enhancement of nanofluid by adding multiwalled carbon \\ nanotubes: Characterization and numerical modeling patterns. Mathematical Methods in the Applied \\ Sciences, \\ Authors \\ Congcong Du, Quyen Nguyen, Omid Malekahmadi, Ali Mardani, Zahra Jokar, Elmira Babadi, Annunziata \\ D'Orazio, Arash Karimipour, Zhixiong Li, and Quang Bach
}




\title{
Thermal conductivity enhancement of nanofluid by adding Multi-Walled Carbon Nano Tubes: Characterization and numerical modeling patterns
}

\author{
Congcong Du ${ }^{1}$ \\ ${ }^{1}$ Hubei Key Laboratory of Power System Design and Test for Electrical Vehicle, Hubei University of
} Arts and Science, Xiangyang, 441053, China.

Quyen Nguyen ${ }^{2}$

${ }^{2}$ Institute of Research and Development, Duy Tan University, Danang 550000, Vietnam.

\section{Omid Malekahmadi ${ }^{3}$}

${ }^{3}$ Department of Mining and Metallurgical Engineering, Yazd University, Yazd, Iran.

\section{Ali Mardani ${ }^{4}$}

${ }^{4}$ New Sciences and Technologies Faculty (FNST), University of Tehran, Tehran, Iran.

\section{Zahra Jokar ${ }^{5}$}

${ }^{5}$ Engineering Department, Payam Noor University, Shiraz, Iran.

\section{Elmira Babadi ${ }^{6}$}

${ }^{6}$ Department of Mechanical Engineering, Najafabad Branch, Islamic Azad University, Najafabad, Iran.

\section{Annunziata D'Orazio ${ }^{7}$}

${ }^{7}$ Dipartimento di Ingegneria Astronautica, Elettrica ed Energetica, Sapienza Università di Roma, Via Eudossiana 18, Roma 00184, Italy.

\section{Arash Karimipour ${ }^{8, *}$}

${ }^{8}$ Sustainable Management of Natural Resources and Environment Research Group, Faculty of Environment and Labour Safety, Ton Duc Thang University, Ho Chi Minh City, Vietnam.

* Corresponding author at: Ton Duc Thang University, Ho Chi Minh City, Vietnam; arashkarimipour@tdtu.edu.vn

\section{Zhixiong Li ${ }^{9,10}$}

${ }^{9}$ MJU-BNUT Department-Joint Research Center on Renewable Energy and Sustainable Marine Platforms, Engineering Research Center of Fujian University for Marine Intelligent Ship Equipment, Minjiang University, Fuzhou 350108, China.

${ }^{10}$ School of Mechanical, Materials, Mechatronic and Biomedical Engineering, University of Wollongong, NSW 2522, Australia.

\section{Quang-Vu Bach ${ }^{11}$}

${ }^{11}$ Sustainable Management of Natural Resources and Environment Research Group, Faculty of Environment and Labour Safety, Ton Duc Thang University, Ho Chi Minh City, Vietnam. 


\begin{abstract}
Nanofluid is divided in two major section, Mono nanofluid (MN) and hybrid nanofluid (HN). MN is created when a solid nano-particle disperses in a fluid, while HN has more than one solid nanomaterial. In this research, Iron (III) Oxide $\left(\mathrm{Fe}_{3} \mathrm{O}_{4}\right)$ is $\mathrm{MN}$ and $\mathrm{Fe}_{3} \mathrm{O}_{4}$ plus Multi-Walled Carbon Nanotube (MWCNT) is HN, while both are mixed and dispersed into the water basefluid. Thermal conductivity (TC) of $\mathrm{Fe}_{3} \mathrm{O}_{4} /$ Water and MWCNT/ $\mathrm{Fe}_{3} \mathrm{O}_{4} /$ Water, were measured after preparation and numerical model performed on the resulted data. Then, X-ray diffraction analysis (XRD) and Energy dispersive X-ray analysis (EDX) were studied for Phase and structural analysis. After that, Field emission scanning electron microscope (FESEM) was studied for Microstructuralobservation of nanoparticles. $\mathrm{MN}$ and $\mathrm{HN}$ TC were studied at temperature ranges of 25 to $50^{\circ} \mathrm{C}$ and volume fractions of 0.2 to $1.0 \%$. For $\mathrm{MN}$ and $\mathrm{HN}$, Thermal conductivity enhancement (TCE) of $32.76 \%$ and $33.23 \%$, was measured at $50^{\circ} \mathrm{C}$ temperature $-1.0 \%$ volume fraction, individually. Different correlations have been calculated for numerical modeling, with $\mathrm{R}^{2}=0.9$ and also, Artificial neural network (ANN) has been modeled with $\mathrm{R}^{2}=0.999$. Deviation of $0.6007 \%$ and $0.6096 \%$, were calculated for given correlations for $\mathrm{MN}$ and $\mathrm{HN}$ individually. Deviation of $0.5862 \%$ and $0.6057 \%$, were calculated for trained models, for MN and HN individually. Thus, by adding MWCNT to $\mathrm{Fe}_{3} \mathrm{O}_{4}-\mathrm{H}_{2} \mathrm{O}$ nanofluid, TC is enhanced $0.47 \%$ and this $\mathrm{HN}$ has agreeable heat transfer potential.
\end{abstract}

Keywords: Thermal conductivity; Numerical modeling; Artificial Neural Network (ANN); MWCNT; Fe3O4; Water 


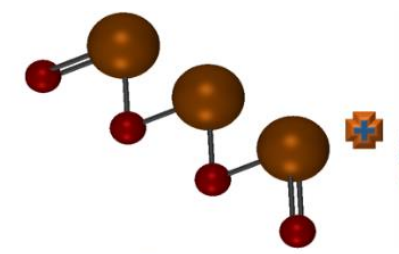

Fe3O4
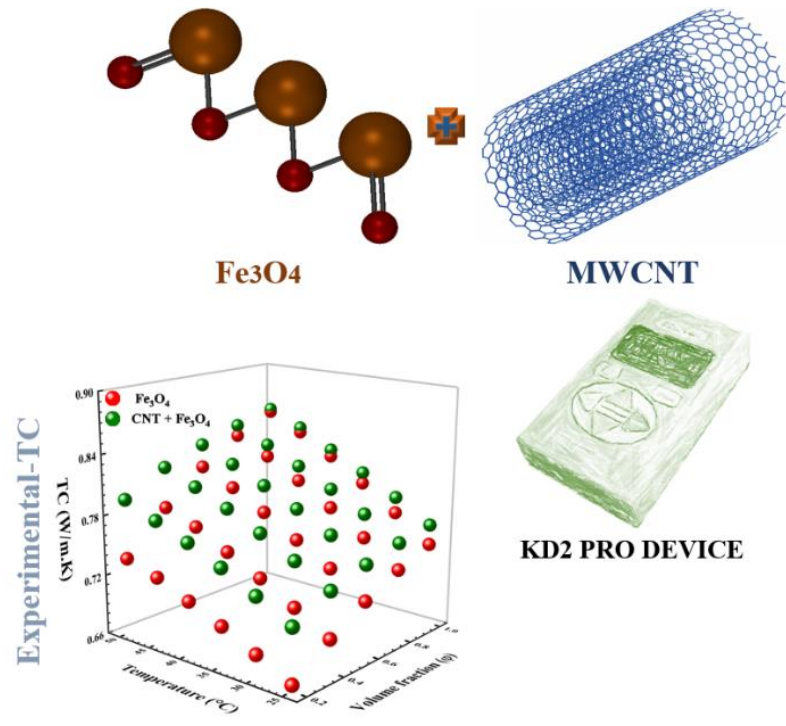

MWCNT

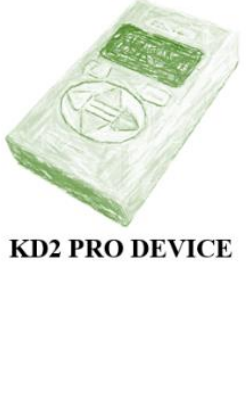

Graphical Abstract

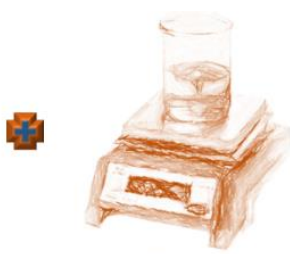

Water

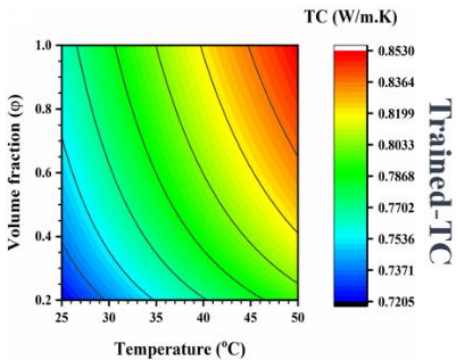

\begin{tabular}{|c|c|c|c|}
\hline & Nomenclature & \multicolumn{2}{|c|}{ Subscripts } \\
\hline XRD & X-ray diffraction analysis & bf & Base Fluid \\
\hline FESEM-EDX & $\begin{array}{c}\text { field emission scanning electron microscope } \\
\text { plus energy dispersive X-ray analysis }\end{array}$ & Nanofluid \\
\hline TC & Thermal Conductivity & Exp & Experimental \\
\hline TCR & Thermal Conductivity Ratio & pred & Predicted \\
\hline TCE & Thermal Conductivity Enhancement & $\mathbf{n p}$ & Nanoparticle \\
\hline MWCNT & Multi-Walled Carbon Nanotube & $\mathbf{r}$ & Ratio \\
\hline
\end{tabular}




\section{Introduction}

Recently, with their great potentialities in different technological fields such as heterogeneous catalysis, magnetic data storage and electrical devices, Carbon nanotubes (CNTs)-based magnetic nanocomposites have drawn considerable research interest. Cunha et al. and Teymourian et al., synthesized the MWCNTs functionalized with $\mathrm{Fe} 3 \mathrm{O} 4$ and $\mathrm{Fe} 3 \mathrm{O} 4$ /MWCNT-COOH, for tissue engineering applications and for the low potential detection of NADH, respectively. As MRI contrasting agent, Wu et al. used the Fe3O4/MWCNT-COOH.

Sumio Iijima discovered Carbon nanotubes (CNTs) in 1991. CNT caused a revolution in different fields of nanotechnology: pharmacology, chemistry, environment, mechanic and electronics. Porous structures and facile surface functionalization are those physical properties which have made the application of the CNTs more attractive [1]. Many modification methods such as chemical, physical or both have been used for the homogeneous dispersion of CNTs in common solvents to improve their solubility. Wide surface of CNTs compared with its length scale in diameter, makes good position for the functionalization and adding different functional groups [2]. Multi-walled carbon nanotubes (MWCNTs) gain more attention compare to single walled carbon nanotubes (SWCNTs), due to their availability in large quantities and low production costs. One of the first CNT nanofluids studied by Choi et al. They reported 160\% increase in TC of 1.0 vol.\% MWNTs dispersed in synthetic poly(a-olefin) oil [3].

Magnetite (Fe3O4), particularly when it is in nano scale, has great significance in different fields. Thus, this material due to its characteristics, inspire researcher's new ideas [4]. Recently, considerable research has been focused on iron oxides, $\gamma-\mathrm{Fe} 2 \mathrm{O} 3$ and $\mathrm{Fe} 3 \mathrm{O} 4$ nanoparticles, which have attracted interest in the field of medical applications such as magnetic sensing, catalysis, high frequency applications, sensors, magneto-optics devices, microwave devices, cancer therapy and medical diagnostics, magnetic resonance imaging (MRI), photomagnetics, radio frequency hyperthermia, drug delivery systems (DDS), data storage, magnetic fluids, high-density digital recording disks and magnetic recording media such as audio and videotape. For such practical uses of magnetic nanoparticles, surface properties of the nanoparticles, magnetic properties and the particle size have great importance [5]. There are different ways to prepare Fe3O4 nanoparticles, such as high temperature decomposition of organic precursors, microemulsions, laser ablation, 
mechanical grinding and arc discharge [6]. These synthetic methods yield Fe3O4 nanoparticles with high crystallinity and narrow size distribution [7].

Recently, industries require fluids which can carry more heat in less time [8]. To improve the performance, energy consumption must be reduced [9]. Thus, fluids with faster heat transfer must be replaced with current fluids. One of these fluids are nanofluids (Introduced by Choi in 1995), which have attracted great concentration in recent years [10]. Nanofluids, are fluids with dispersed nano-size particles into basefluids such as Water, Oil and Ethylene Glycol [11]. Thermal conductivity increases or decrease if any nano-size particle dispersed into a fluid. After Choi, One, two- and three- dimensional nanomaterials such as fibers, sheets and particles and also different basefluids investigated to realize the effect of each material on thermal conductivity enhancement. There are two types of Nanofluids, mono and hybrid [12]. Mono-nanofluid is prepared by dispersion of one nanoparticle in a fluid, but hybrid-nanofluid is composed of more than one solid particle. In fact, each nanoparticle has its own properties [13]. Thus, this is possible to make use of different nanoparticles properties at the same time. Nanofluids can be used in different industrial applications: systems of engine cooling, electronic device cooling, heating and cooling system for buildings [14].

Recently, Artificial neural network was used in transformers heat analysis. The ANN, as a new parameter to investigate in each research, can model the data in specific range of temperature or volume fraction, with more than 1000 data. This means the highly reduction in the experiment costs. The ANN can model complex patterns by using simple computations. Thus, in nanofluid study, ANN modeling can be useful.

The aim of this research is to investigate hybrid nanofluid's thermal conductivity. Thus, MultiWalled Carbon Nanotube and Iron (III) Oxide nanoparticles dispersed in Water, and hybrid nanofluid (with composition of MWCNT 50\% / $\mathrm{Fe}_{3} \mathrm{O}_{4} 50 \%$ ) was prepared at different volume fractions up to $1.0 \%$. After that, experiments done at different temperatures up to $50^{\circ} \mathrm{C}$ (by hotwire method). With using available data and curve fitting method, new correlations have been offered to calculate thermal conductivity of Iron (III) Oxide /Water MN and MWCNT/Iron (III) Oxide /Water HN in specified range of volume fraction and temperature [15]. Also, artificial neural network was modeled for both $\mathrm{MN}$ and $\mathrm{HN}$ to predict TC behavior in other volume fractions and temperatures. 


\section{Materials and Methods}

\subsection{Materials}

For nano-size solid materials, Multi-Walled Carbon Nanotube and Iron (III) Oxide were used. Figure 1, shows the 3D-chemical structure of MWCNT and $\mathrm{Fe}_{3} \mathrm{O}_{4}$. MWCNT was purchased from nano-bazar, Inc with length of $30 \mathrm{um}$, ID 5-10 nm and OD 10-20 nm with COOH content of 2.0 wt $\%$. $\mathrm{Fe}_{3} \mathrm{O}_{4}$ was purchased from US Research Nanomaterials, Inc. Table 1, shows thermophysical properties of nanoparticles and basefluid. X-ray diffraction analysis was studied by D8ADVANCE Bruker X-ray diffractometer. Field emission scanning electron microscope images were taken by NOVA NanoSEM to observe sample morphology. Also, to certify XRD results, Energy dispersive $\mathrm{X}$-ray analysis was used.

Table 1. Thermophysical Properties of Basefluid and Nanoparticles

\begin{tabular}{|cccc|}
\hline Properties & Water (Base fluid) & $\begin{array}{c}\text { Iron (III) Oxide } \\
\text { (Nanoparticle 50\%) }\end{array}$ & $\begin{array}{c}\text { Multi-Walled CNT } \\
\text { (Nanoparticle 50\%) }\end{array}$ \\
\hline Chemical formula & $\mathrm{H}_{2} \mathrm{O}$ & $\mathrm{Fe} 3 \mathrm{O} 4 ; \mathrm{FeO} . \mathrm{Fe} 2 \mathrm{O} 3$ & $\mathrm{C}$ \\
Appearance & --- & Lustrous black & Black \\
Purity $(\%)$ & Distilled water & $97 \%$ & 12.011 \\
Molar mass $\left(\mathrm{g} / \mathrm{mol}^{2}\right)$ & 18.0153 & 231.533 & 2.6 \\
Density $\left(\mathrm{gr} / \mathrm{m}^{3}\right)$ & 0.998 & 5.2 & This paper \\
Thermal conductivity $(\mathrm{W} / \mathrm{m} \cdot \mathrm{K})$ & $\sim 0.6\left(@ 20^{\circ} \mathrm{C}\right)$ & & \multicolumn{2}{c}{} \\
\hline
\end{tabular}

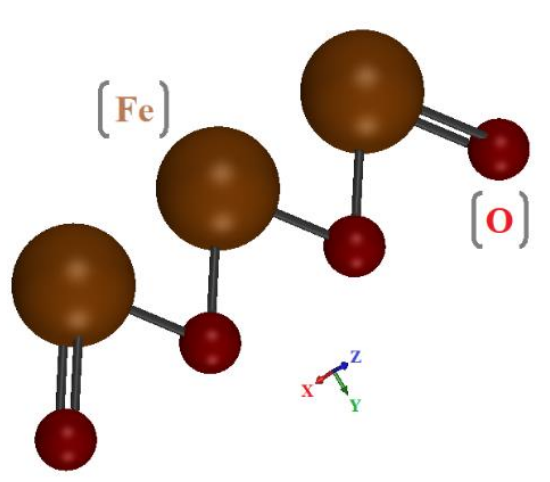

Iron (III) Oxide

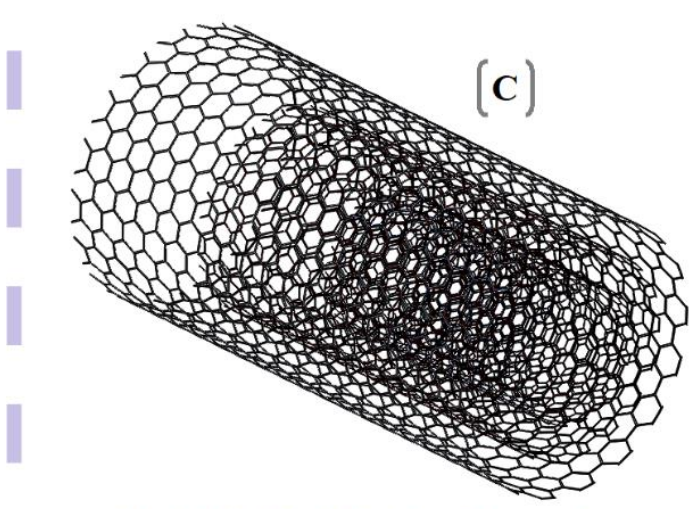

Multi-Walled Carbon Nanotube 
Figure 1. 3D-schematic form of Multi-Walled Carbon Nanotube (MWCNT) and Iron (III) Oxide $\left(\mathrm{Fe}_{3} \mathrm{O}_{4}\right)$

\subsection{Nanofluid Preparation}

In this research, mono and hybrid nanofluid prepared separately, to measure nanofluid's thermophysical properties. $\mathrm{Fe}_{3} \mathrm{O}_{4}$ as mono nanofluid, and $\mathrm{Fe}_{3} \mathrm{O}_{4}$ plus MWCNT (equal 50-50) as hybrid nanofluid, dispersed into water [16]. Various percentages of mono and hybrid nanofluid $(0.2,0.4,0.6,0.8$ and $1.0 \mathrm{vol} \%)$ were prepared and then, $\mathrm{pH}$ meter, magnetic stirring and sonication were used to break agglomerations between nanoparticles to reach a stable suspension. To made and test this stable suspension, 120min magnetic stirring and 35min ultrasonic (400 W - $24 \mathrm{kHz})$, were done.

\subsection{Thermal Conductivity Measurement}

To measure thermo properties of mono and hybrid nanofluid, a KD2 Pro device (Decagon Devices, Inc., USA) was used. This device use hot-wire method with 5\% error, and it needs to be calibrated with pure water. Mono and hybrid nanofluid containers placed at temp. bath and then, a single needle (stainless steel) sensor -KS.1- was inserted into containers, independently [17]. Thermal conductivity was measured 4-times, for each temperature $\left(25,30,35,40,45\right.$ and $\left.50^{\circ} \mathrm{C}\right)$, independently [18].

Thermal conductivity ratio (TCR) and Thermal conductivity enhancement (TCE) are calculated by equations 1 and 2 , respectively.

Thermal conductivity ratio $=\frac{k_{n f}}{k_{b f}}$

Thermal conductivity enhancement $(\%)=\frac{k_{n f}-k_{b f}}{k_{b f}} * 100$

Where $k$ is thermal conductivity (TC) of nanofluid. Also, "bf" is basefluid and " ${ }_{n f}$ " is nanofluid. 


\section{Result and Discussion}

\subsection{Materials}

\subsubsection{Phase and Structural Analysis}

$X R D$

Figure 2, displays the X-ray diffraction analysis of $\mathrm{MWCNT}-\mathrm{COOH}$ and $\mathrm{Fe}_{3} \mathrm{O}_{4}$. An intense characteristic peak at (002) plane, $2 \theta=26.04^{\circ}$ with interlayer spacing (Via Bragg's law $\mathrm{Cu} \mathrm{K} \alpha$ : $1.541^{\circ} \AA$ A wavelength) of $3.418 \AA$ d-spacing is visible in the pattern [19]. Also, low-intensity peaks which indicates the crystalline structure of MWCNT are in (100), (004), and (110) planes, at $2 \theta=$ $42.64^{\circ}, 2 \theta=53.18^{\circ}$ and $2 \theta=78.22^{\circ}$ [20]. For the $\mathrm{Fe}_{3} \mathrm{O}_{4}$ [21] XRD pattern of the sample, shows identical to pure magnetite (96-900-5840) with Cubic Crystal system. As it can be seen, (220) plane at $2 \theta=29.98^{\circ},(311)$ plane at $2 \theta=35.45^{\circ}$ and with $2.52 \AA$ d-spacing, (400) plane at $2 \theta=$ $43.13^{\circ}(422)$ plane at $2 \theta=53.44^{\circ}(511)$ plane at $2 \theta=56.94^{\circ}(440)$ plane at $2 \theta=62.61^{\circ}$ are the sample peaks.

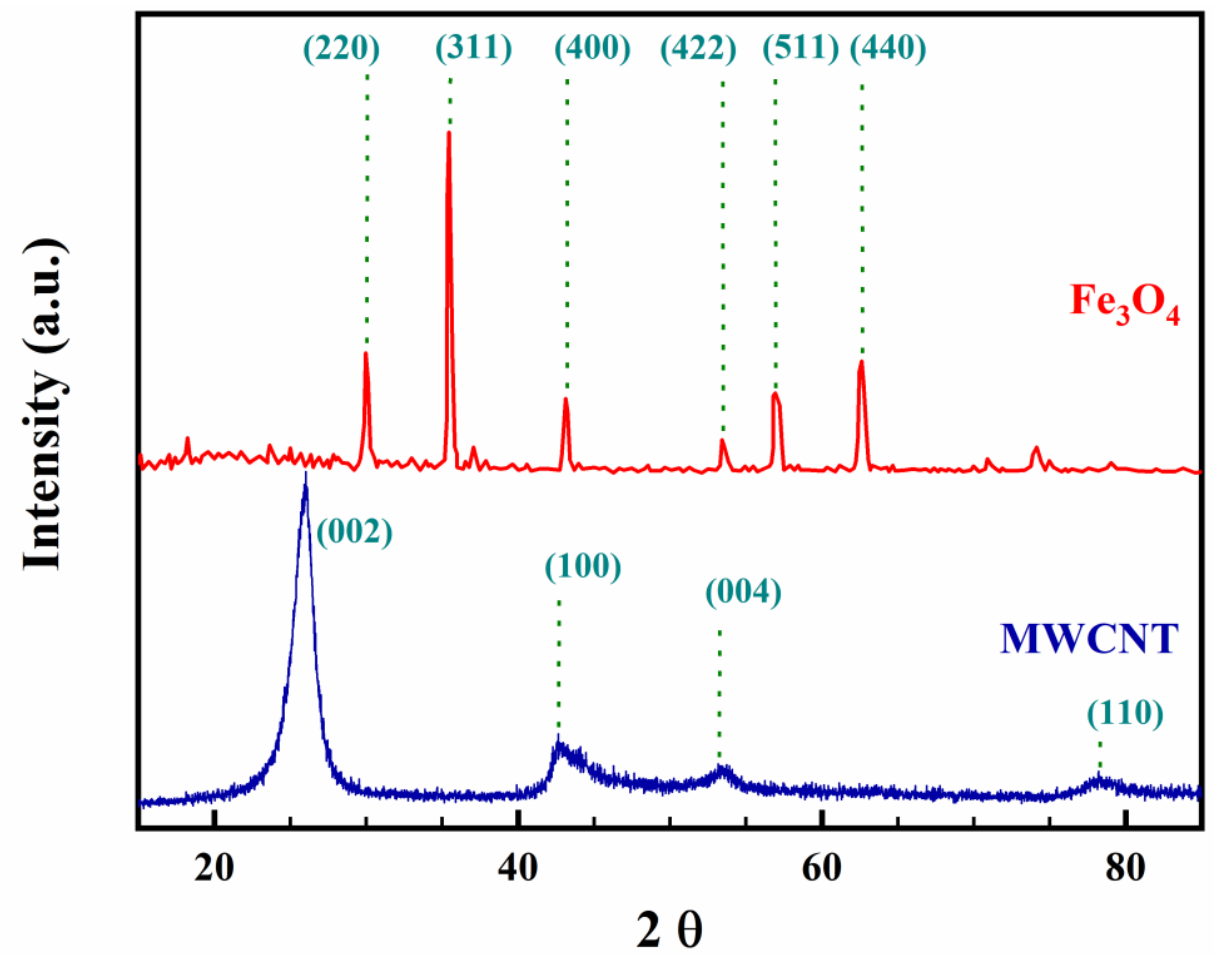

Figure 2. XRD of Multi-Walled Carbon Nanotube (MWCNT) and Iron (III) Oxide $\left(\mathrm{Fe}_{3} \mathrm{O}_{4}\right)$ 


\subsubsection{Microstructural Observations}

\section{FESEM and EDX}

Figure 3 shows Field emission scanning electron microscope image of MWCNT with the magnification scales of 3000 (left) and $500 \mathrm{~nm}$. 0D nanomaterials are nanoparticles and in 1D nanomaterials, one dimension is outside the nanoscale. As it can be seen, MW Carbon Nanotubes has one-dimension structure as like as nanorods, and nanowires. From the figure, nanotubes have nanometer scale which is under $100 \mathrm{~nm}$ [22]. MWCNT has a rough surface structure due to the attachment of oxygenated functional groups on its surface after acid treatment [23] and a smooth surface with bundles of tangled tubes. The chemical compositions of MWCNT was verified by using Two-point Energy dispersive X-ray analysis [24]. Figure 4 and Table 2 show 2-point EDX of MWCNT. MWCNT had impurities, however after acid functionalization [25], these metal impurities were removed. MWCNT at point-A contains utmost 95.63 at.\% Carbon, 2.63 at.\% Oxygen and 1.74 at.\% Nitrogen. MWCNT at point-B contains utmost 96.49 at.\% Carbon, 2.87 at.\% Oxygen and 0.64 at.\% Nitrogen.
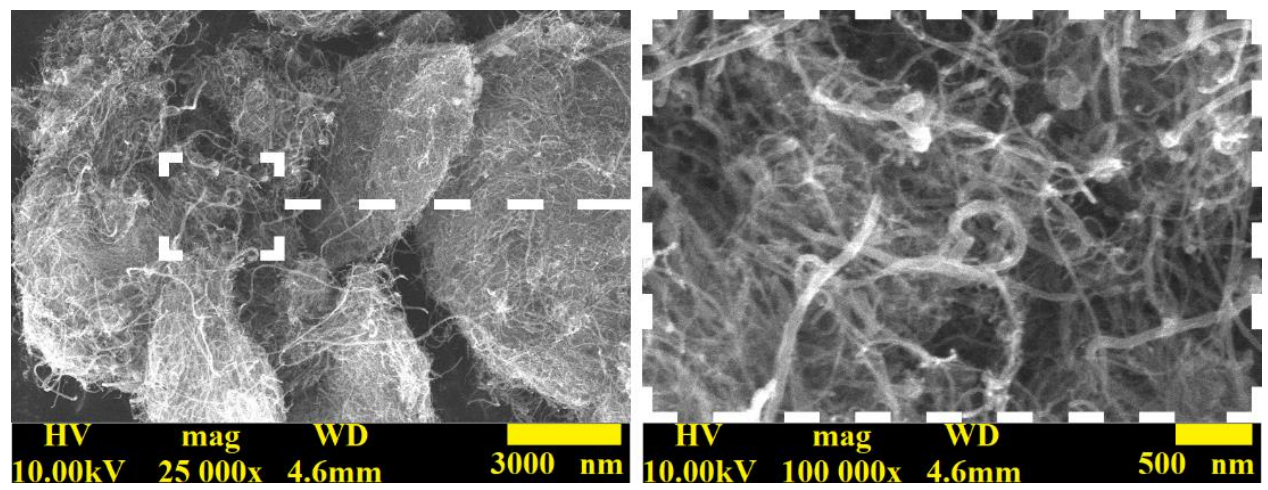

Figure 3. FESEM of Multi-Walled Carbon Nanotube (MWCNT) 

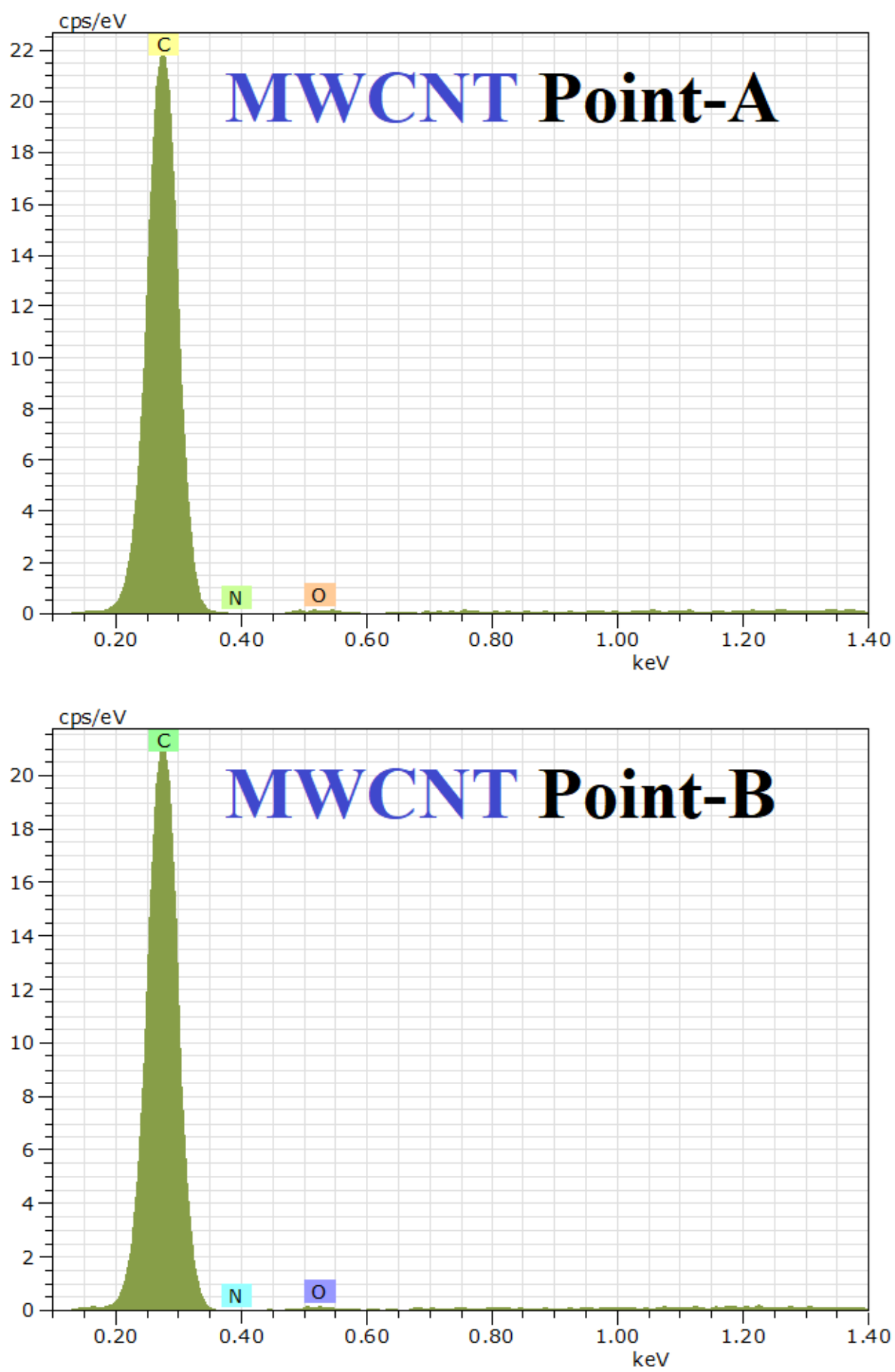

Figure 4. EDX 2-point of Multi-Walled Carbon Nanotube (MWCNT)

Table 2. EDX 2-point data for Multi-Walled Carbon Nanotube (MWCNT) 


\begin{tabular}{|c|c|c|c|c|}
\hline \multicolumn{5}{|c|}{ MWCNT - First Point } \\
\hline \multicolumn{5}{|c|}{ El AN Series unn. C norm. C Atom. C Error (1 Sigma) } \\
\hline & [wt.\%] & [wt.\%] & [at.\%] & [wt.\%] \\
\hline $\mathrm{C}$ & 95.63 & 95.63 & 96.50 & 12.65 \\
\hline $\mathrm{O}$ & 2.63 & 2.63 & 1.99 & 1.37 \\
\hline \multirow{2}{*}{$\mathrm{N}$} & 1.74 & 1.74 & 1.51 & 1.68 \\
\hline & 100 & 100 & 100 & \\
\hline \multicolumn{5}{|c|}{ MWCNT - Second Point } \\
\hline \multicolumn{5}{|c|}{ El AN Series unn. C norm. C Atom. C Error (1 Sigma) } \\
\hline & [wt.\%] & [wt.\%] & [at.\%] & [wt.\%] \\
\hline $\mathrm{C}$ & 96.49 & 96.49 & 97.28 & 13.09 \\
\hline $\mathrm{O}$ & 2.87 & 2.87 & 2.17 & 1.56 \\
\hline \multirow[t]{2}{*}{$\mathrm{N}$} & 0.64 & 0.64 & 0.55 & 1.09 \\
\hline & 100 & 100 & 100 & \\
\hline
\end{tabular}

\subsection{Nanofluid Preparation}

\subsubsection{Thermal Conductivity}

\section{Validation}

KD2-Pro device was calibrated with glycerin and maximum error of $0.47 \%$ was calculated, at $\mathrm{T}=45^{\circ} \mathrm{C}$. This error was acceptable based on KD2-Pro manufacturer manual [26]. After that, water (basefluid) thermal conductivity was measured. Then in Figure 5, the data obtained from ASHRAE handbook [27] for thermal conductivity compared with experimental data.

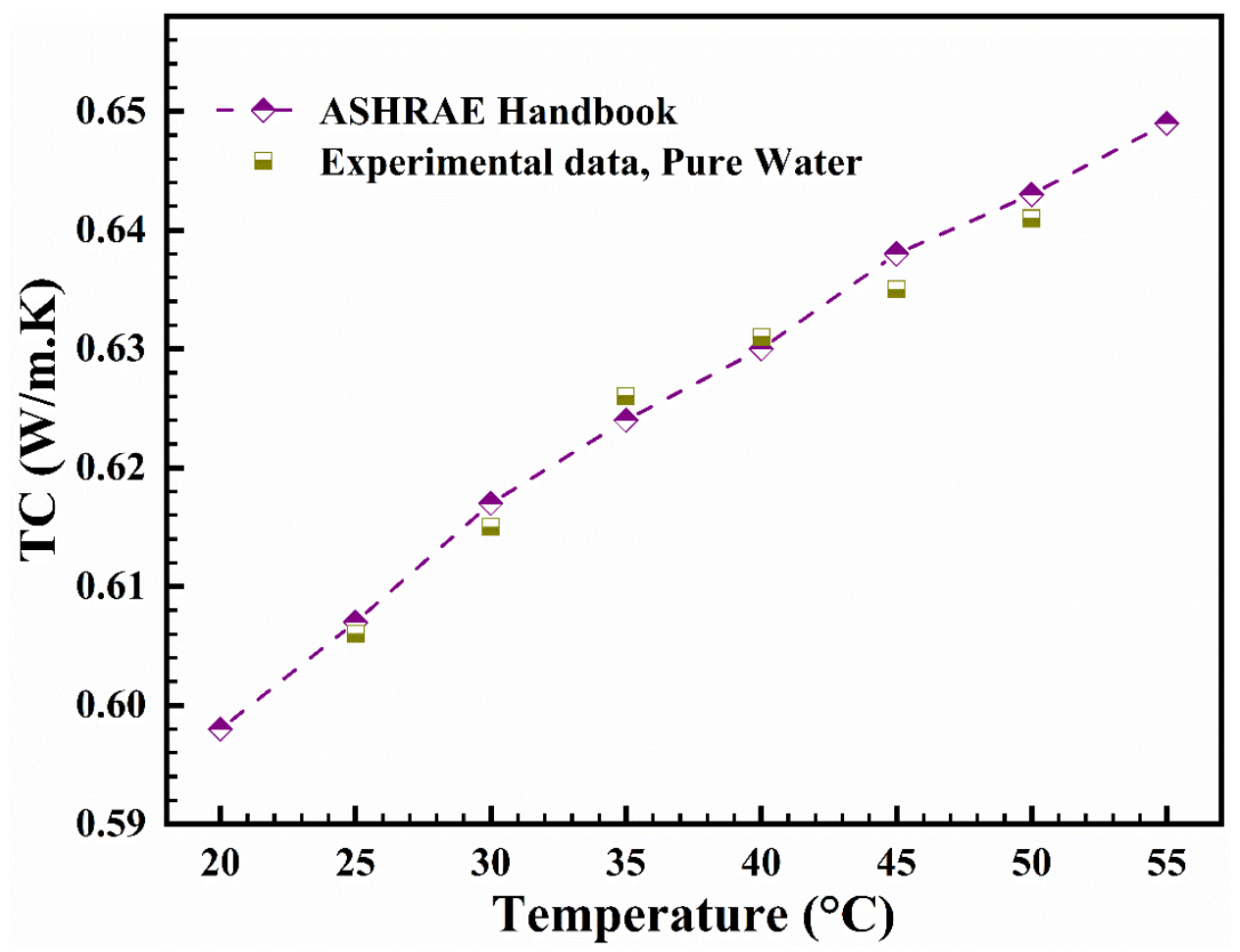


Figure 5. Pure water validation - Experimental results and ASHRAE handbook [27]

\section{Volume Fraction and Temperature Effect}

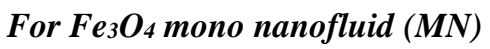

Thermal conductivity of $\mathrm{Fe}_{3} \mathrm{O}_{4} / \mathrm{H}_{2} \mathrm{O} \mathrm{MN}$ was measured at volume fraction ranges of 0.2 to $1.0 \%$ and temperature ranges of 25 to $50^{\circ} \mathrm{C}$ [28]. Temperature and volume fraction factors in thermal conductivity, were considered for this $\mathrm{MN}$ [29]. Figure 6 displays $\mathrm{MN}$ thermal conductivity by volume fraction in various temperatures while Figure 7 shows thermal conductivity by temperature in different volume fractions. It is obvious that, thermal conductivity was raised with increasement in temperature and volume fraction. Results pointed out that the trend for temperature and volume fraction is not similar [30]. It means that in higher volume fractions, temperature has more effect, For instance:

For $\mathrm{MN} 0.2 \mathrm{Vol} \%$, Thermal conductivity raised $0.071 \mathrm{~W} / \mathrm{m} . \mathrm{k}\left(0.666\right.$ to 0.737 from $25^{\circ} \mathrm{C}$ to $\left.50^{\circ} \mathrm{C}\right)$;

For $\mathrm{MN} 1.0 \mathrm{Vol} \%$, Thermal conductivity raised $0.108 \mathrm{~W} / \mathrm{m} . \mathrm{k}\left(0.743\right.$ to 0.851 from $25^{\circ} \mathrm{C}$ to $\left.50^{\circ} \mathrm{C}\right)$; Which means when volume fraction increased about 5.0 times, Thermal conductivity raised about 1.52 times. 

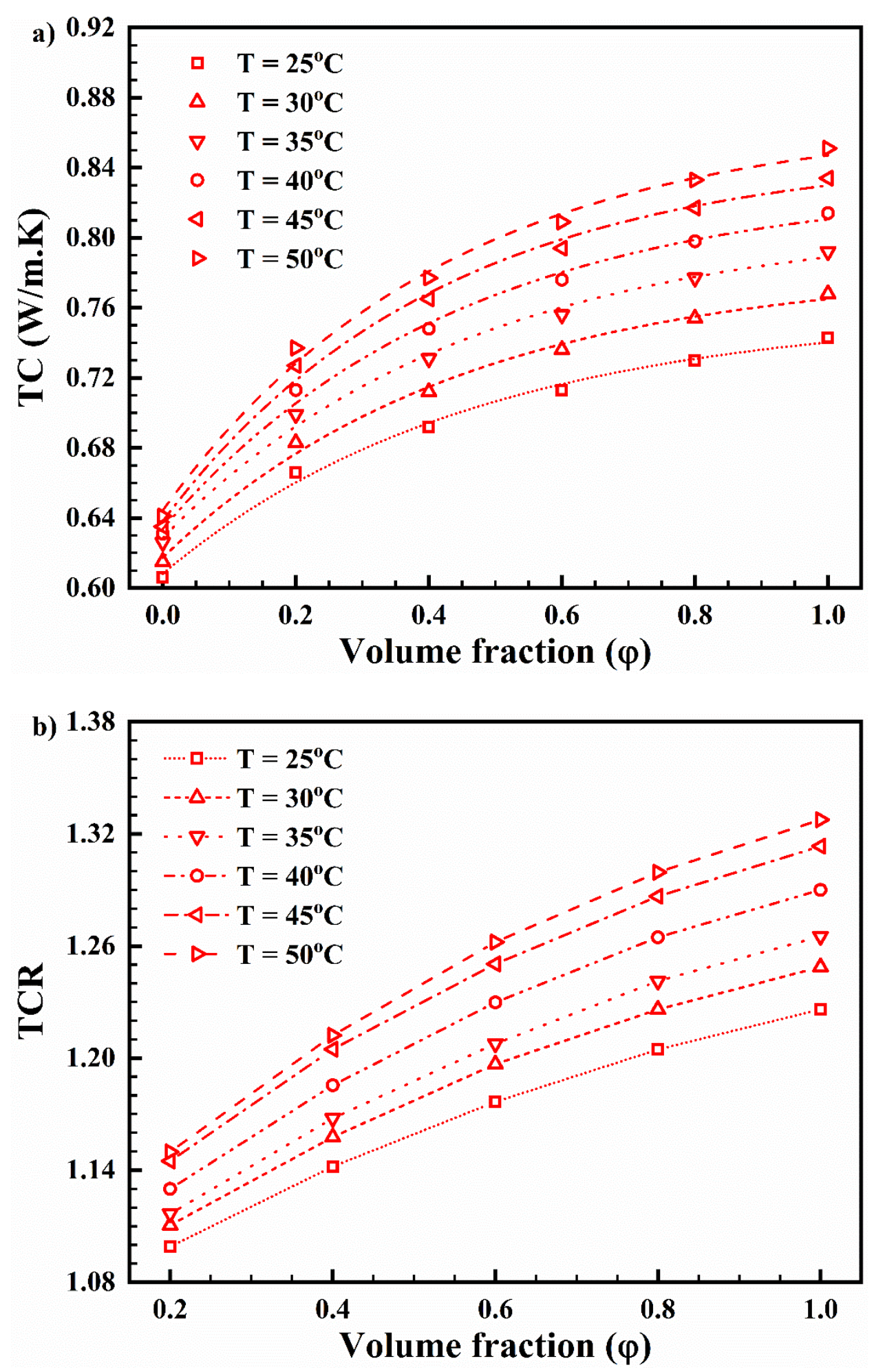

Figure 6. Changes in (a) Thermal conductivity and (b) Thermal conductivity ratio - by volume fraction at different temperatures 

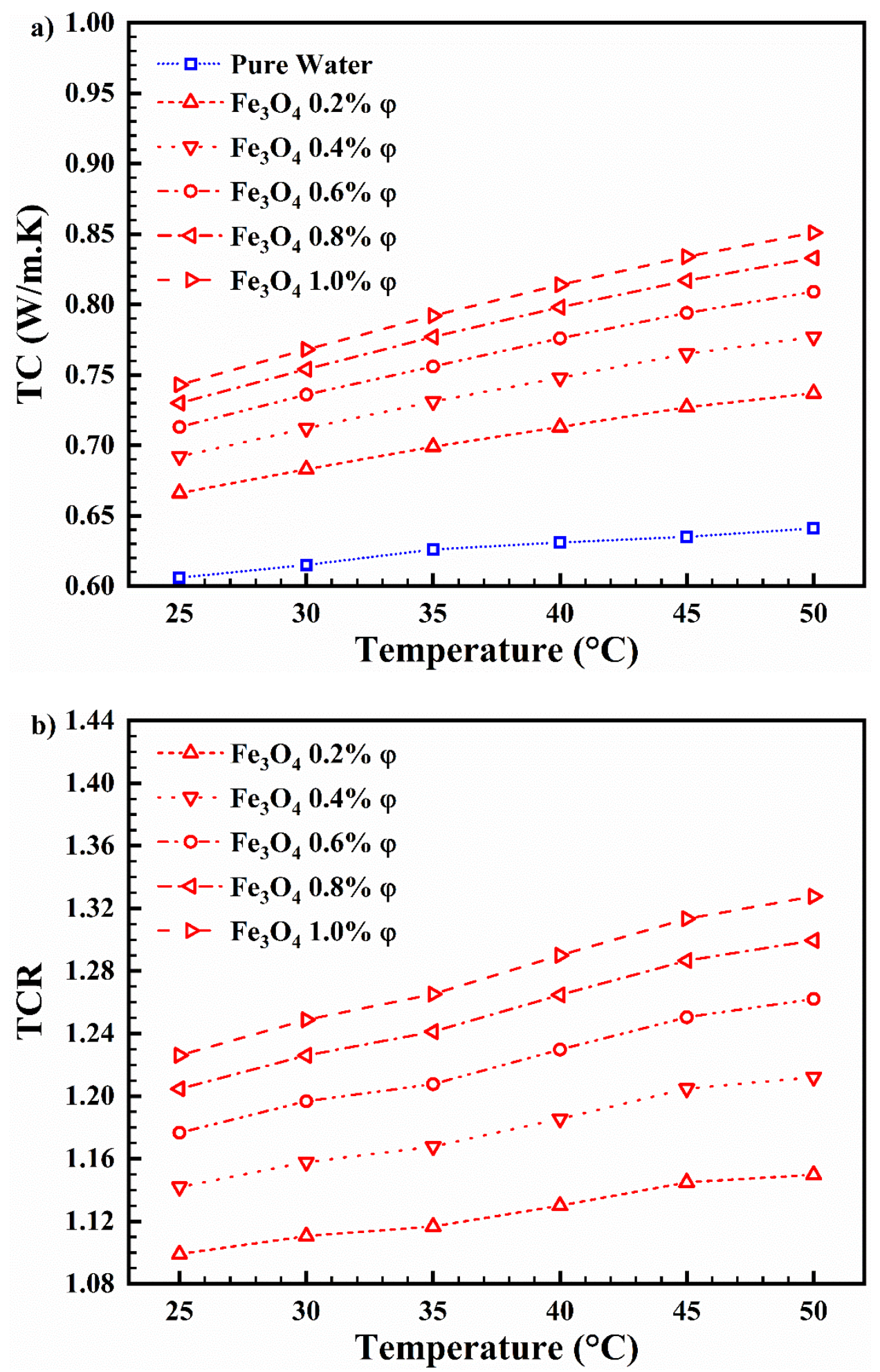

Figure 7. Changes in (a) Thermal conductivity and (b) Thermal conductivity ratio - by temperature at different volume fractions 


\section{For $\mathrm{CNT} / \mathrm{Fe}_{3} \mathrm{O}_{4} \mathrm{Hybrid}$ nanofluid (HN)}

After that by adding MWCNT, thermal conductivity of MWCNT/ $\mathrm{Fe}_{3} \mathrm{O}_{4} / \mathrm{H}_{2} \mathrm{O} \mathrm{HN}$ was measured at volume fraction ranges of 0.2 to $1.0 \%$ and temperature ranges of 25 to $50^{\circ} \mathrm{C}$. Temperature and volume fraction factors in thermal conductivity, were considered for this HN [31]. Figure 8 displays HN thermal conductivity by volume fraction in various temperatures while Figure 9 shows thermal conductivity by temperature in different volume fractions. It is obvious that, thermal conductivity raised with increasement in temperature and volume fraction [32]. Results pointed out that the trend for temperature and volume fraction is not similar. It means that in higher volume fractions, temperature has more effect, For instance:

For $\mathrm{HN} 0.2 \mathrm{Vol} \%$, Thermal conductivity raised $0.076 \mathrm{~W} / \mathrm{m} . \mathrm{k}\left(0.72\right.$ to 0.796 from $25^{\circ} \mathrm{C}$ to $\left.50^{\circ} \mathrm{C}\right)$;

For HN $1.0 \mathrm{Vol} \%$, Thermal conductivity raised $0.091 \mathrm{~W} / \mathrm{m} . \mathrm{k}\left(0.763\right.$ to 0.854 from $25^{\circ} \mathrm{C}$ to $\left.50^{\circ} \mathrm{C}\right)$;

Which means when volume fraction increased about 5.0 times, Thermal conductivity raised about 1.197 times.

Figure 10, compare thermal conductivity of $\mathrm{MN}$ and $\mathrm{HN}$ by both volume fraction and temperature in three- dimensional status.

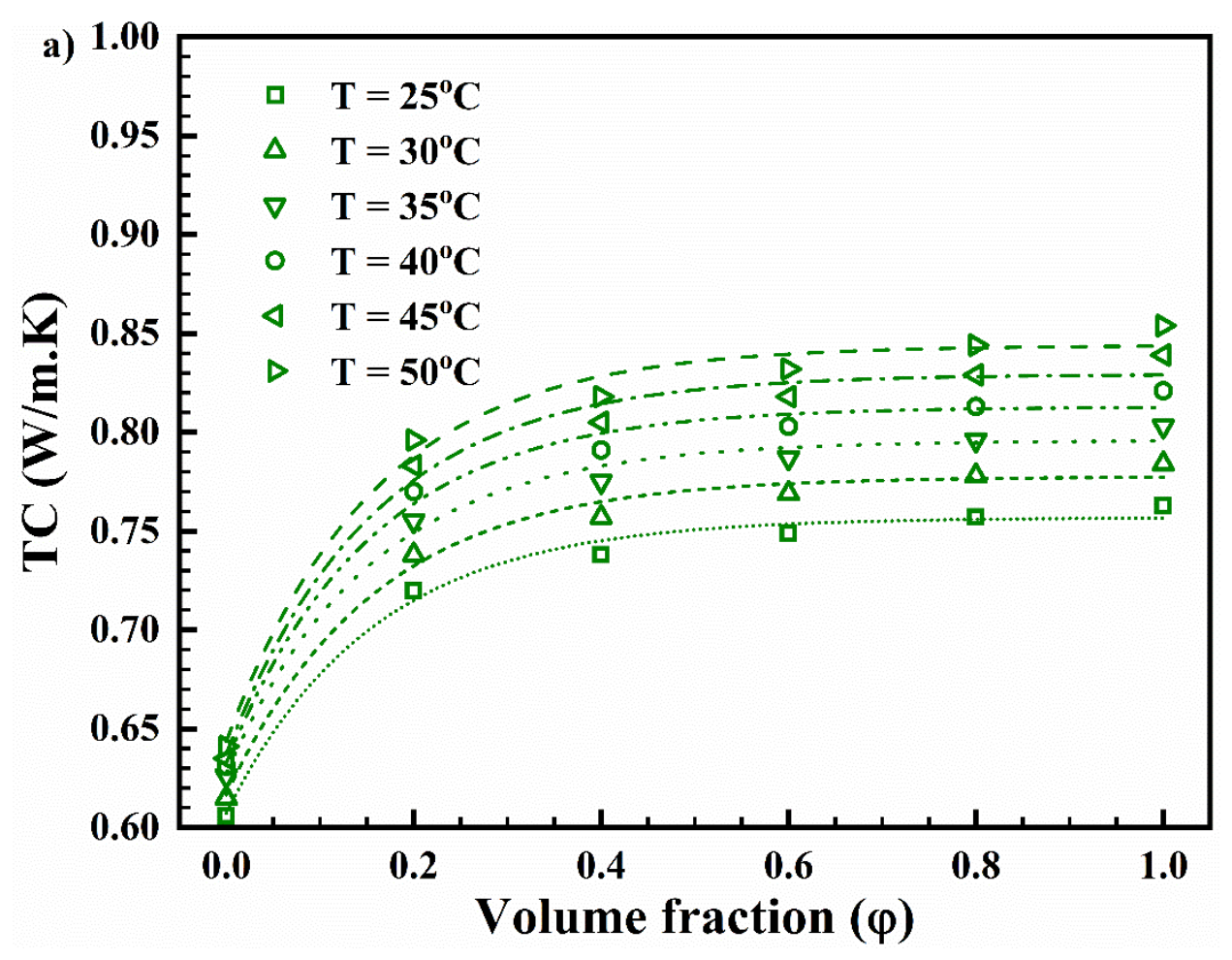




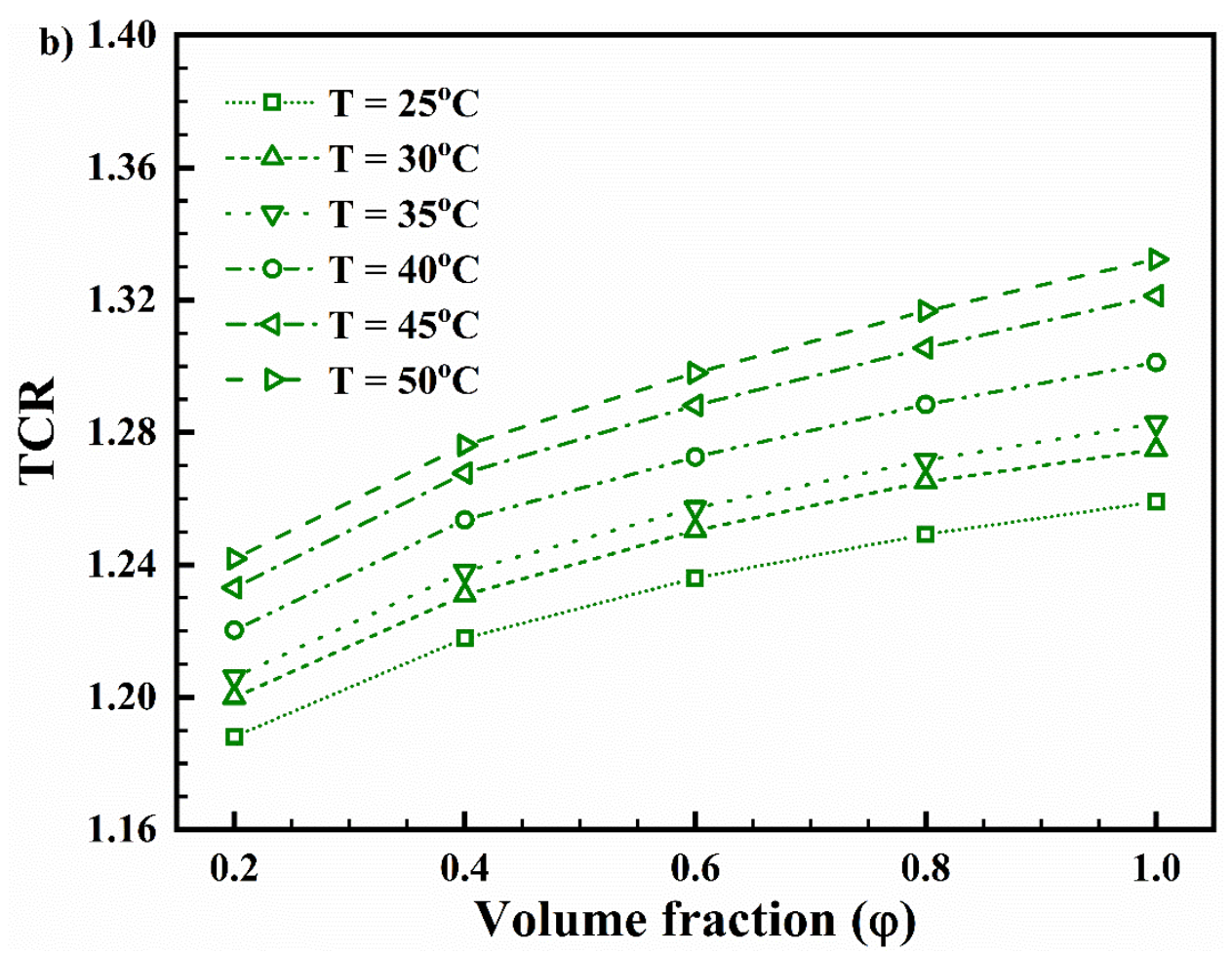

Figure 8. Changes in (a) Thermal conductivity and (b) Thermal conductivity ratio - by volume fraction at different temperatures

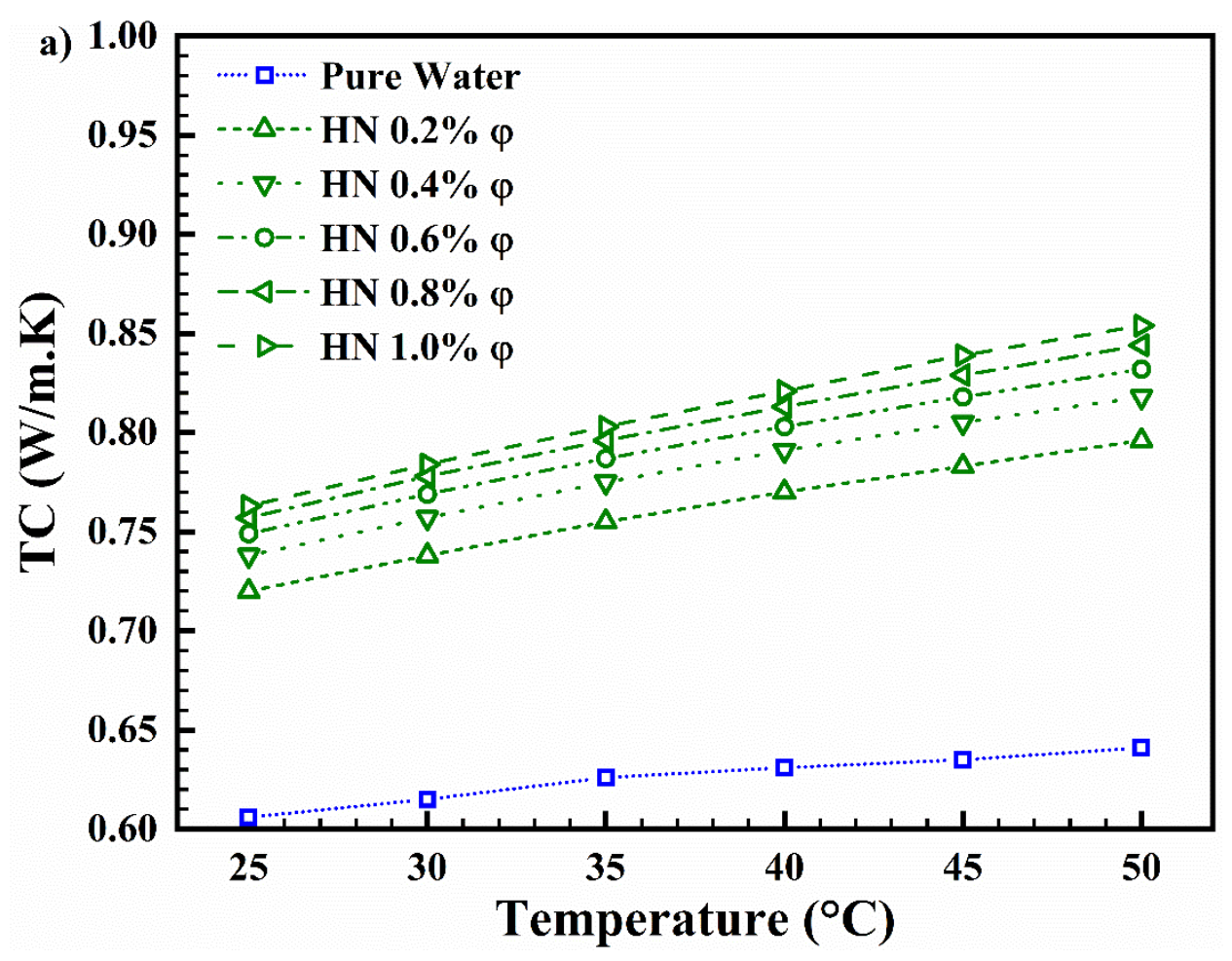




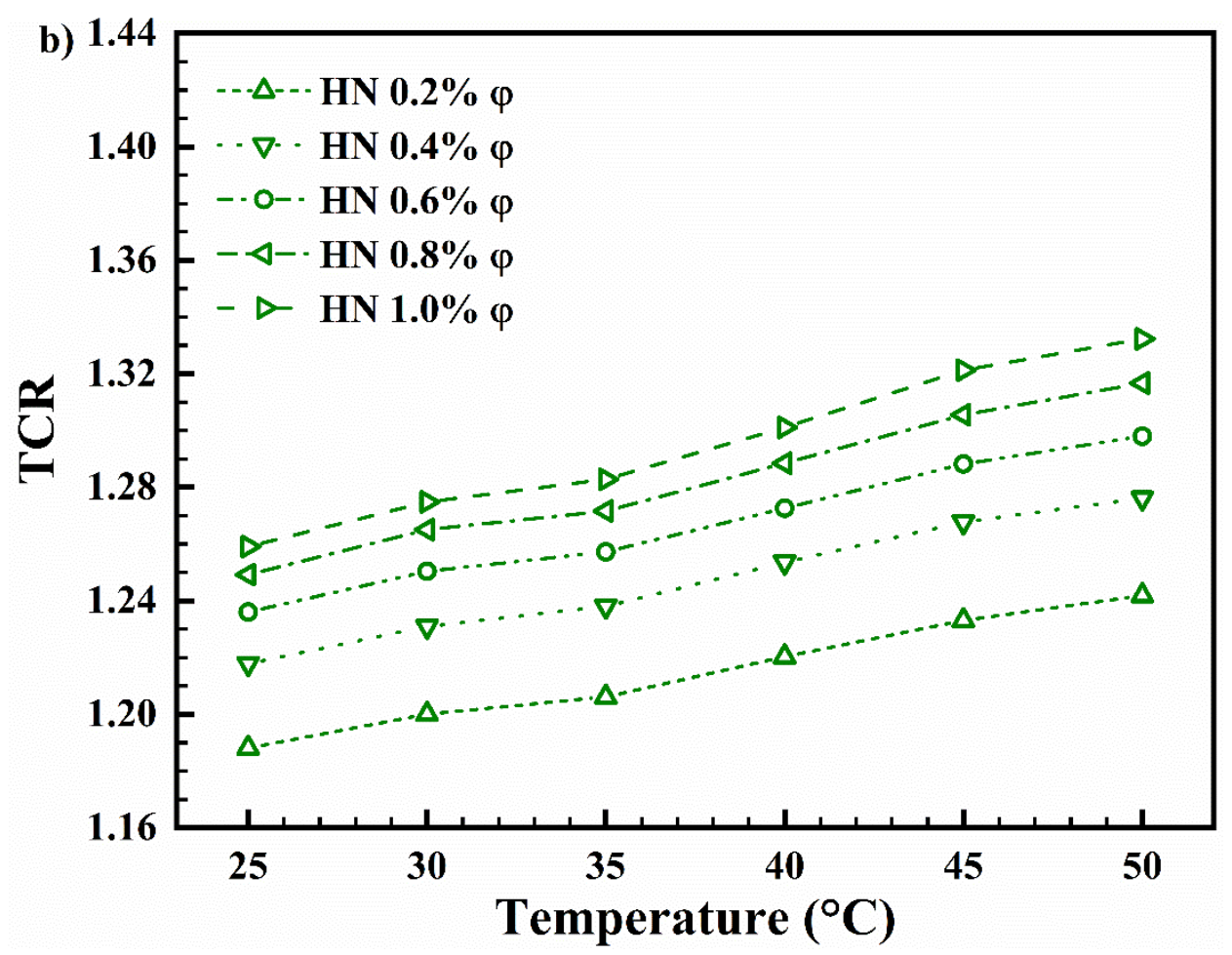

Figure 9. Changes in (a) Thermal conductivity and (b) Thermal conductivity ratio - by temperature at different volume fractions 


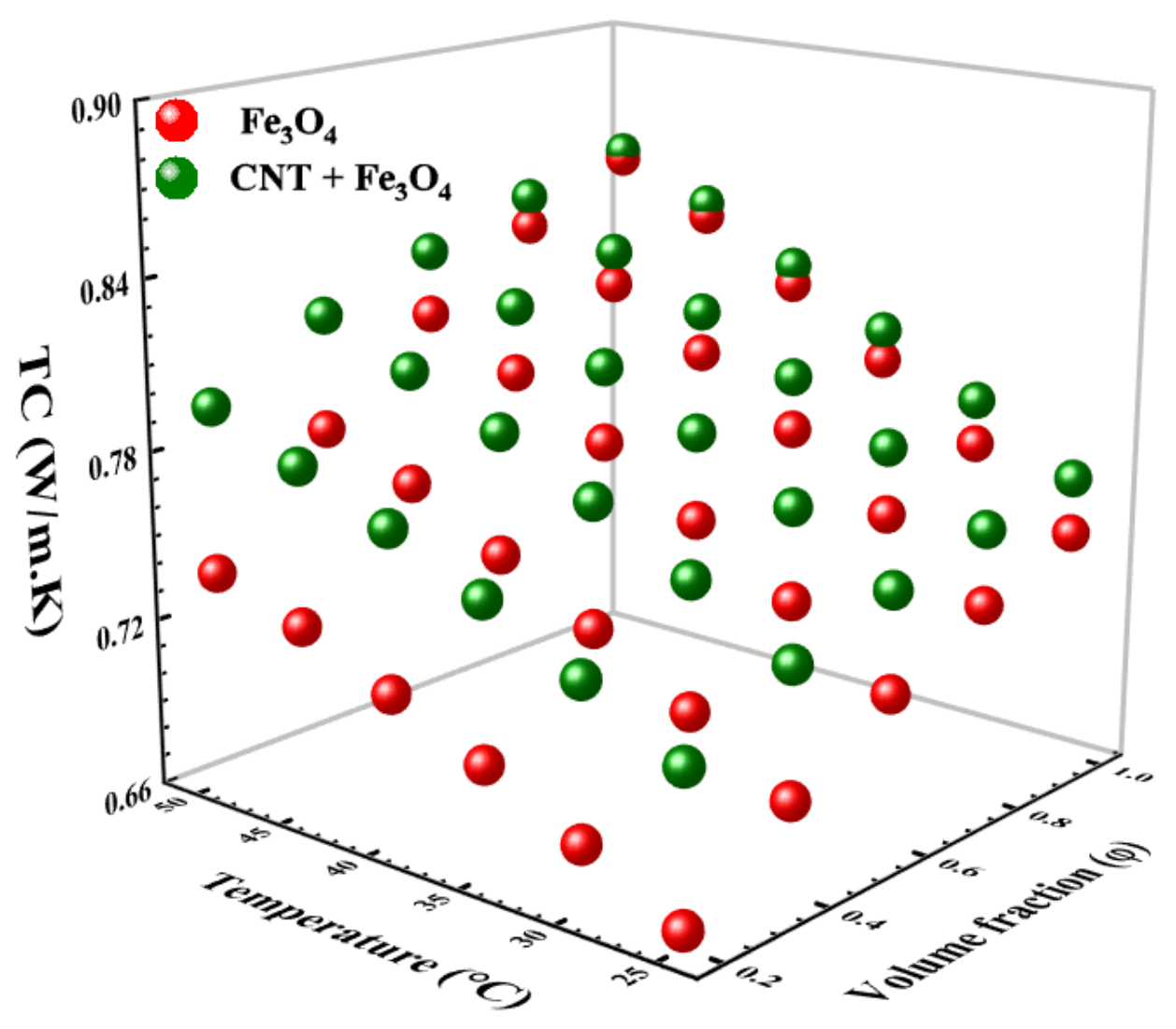

Figure 10. 3D-Thermal conductivity data compare at various nanofluid volume fractions and temperatures

\section{Thermal Conductivity Enhancement}

When the temperature increase, interactions between the nanoparticles (NPs) increase too. Brownian motion refers to augmentation in number of suspended NPs by increment in volume fraction, which leads to growth in surface to volume ratio [33].

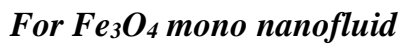

Figure 11 shows the thermal conductivity enhancement (TCE) of MN. It can be seen that the maximum TCE for $\mathrm{Fe}_{3} \mathrm{O}_{4} /$ Water mono nanofluid is about $32.76 \%$ which is at the most volume fraction and temperature. Nanoparticles number and thus, Brownian motion increase at upper temperature and volume fraction. So, TCE percentage of MN at this state, is more than that at lower temperature [34].

For $\mathrm{MN} 0.2 \mathrm{Vol} \%$, Thermal conductivity enhancement raised $5.08 \%\left(9.9\right.$ to 14.98 from $25^{\circ} \mathrm{C}$ to $\left.50^{\circ} \mathrm{C}\right)$ 
For MN $1.0 \mathrm{Vol} \%$, Thermal conductivity enhancement raised $10.16 \%$ (22.6 to 32.76 from $25^{\circ} \mathrm{C}$ to $\left.50^{\circ} \mathrm{C}\right)$

Which means when volume fraction increased about $0.8 \%$, Thermal conductivity enhancement raised about 5.08\% [35].

Thermal conductivity enhancement of various particles in MN noticed at Table 3.

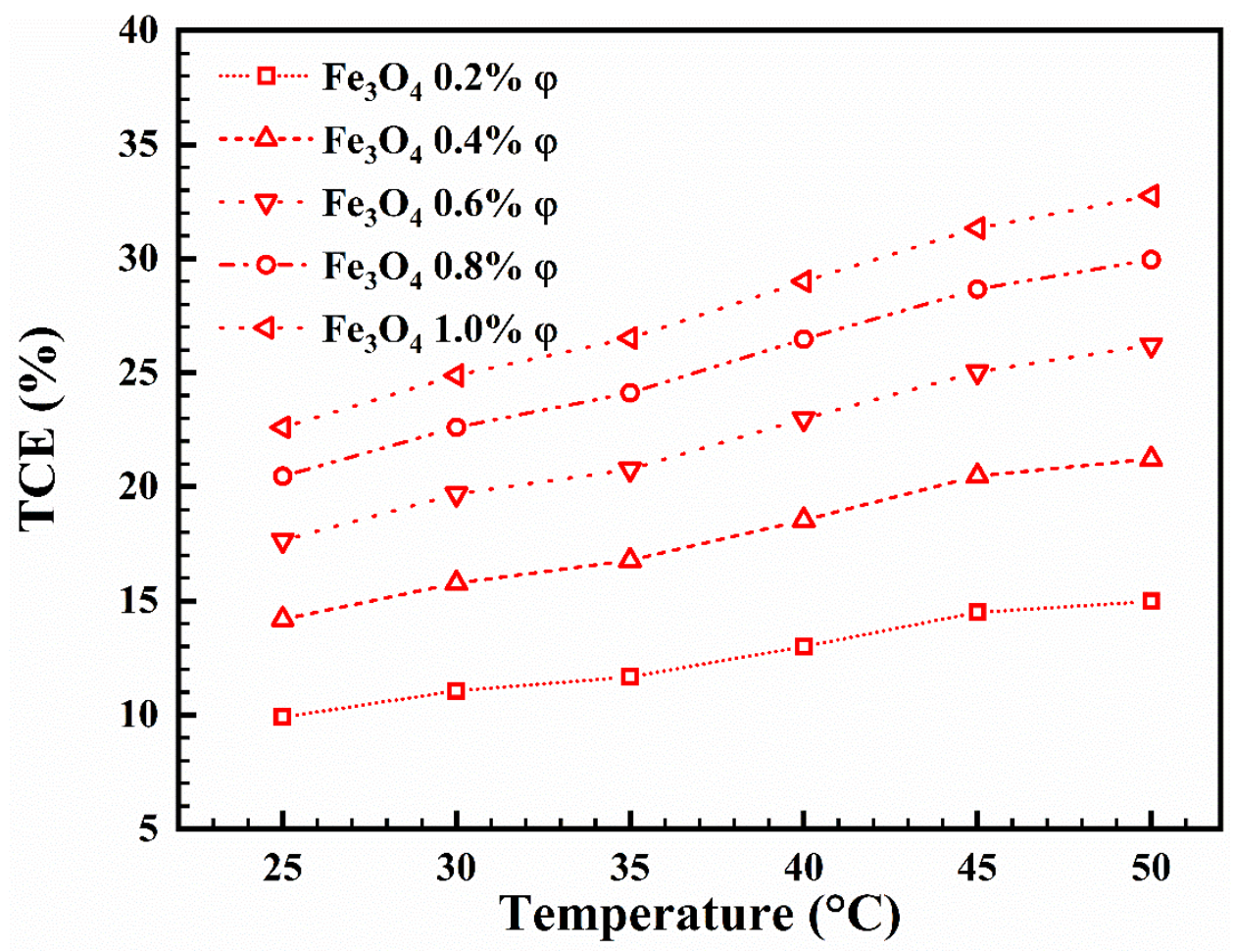

Figure 11. Variations in Thermal conductivity enhancement by nanofluid temperature at different volume fractions

Table 3. Thermal conductivity enhancement of various particles in mono nanofluids

\begin{tabular}{cccc}
\hline Dispersed particles & Basefluid & Maximum enhancement/\% & Ref. \\
\hline $\mathrm{Fe}_{3} \mathrm{O}_{4}$ & Water & $32.76 \%$ @ $1.0 \mathrm{vol} \%$ & This Work \\
\hline Graphene & Water & $10.3 \%$ @ $0.02 \mathrm{vol} \%$ & {$[36]$} \\
\hline Graphene Oxide & Water & $19.9 \% @ 0.5 \mathrm{wt} \%$ & {$[37]$} \\
\hline Graphene & Water & $25 \% @ 0.1 \mathrm{wt} \%$ & {$[38]$} \\
\hline Graphene & Water & $27 \% @ 0.2 \mathrm{vol} \%$ & {$[39]$} \\
\hline MWCNT & Water & 64.0 & {$[40]$} \\
\hline MWCNT & Water & 38.0 & {$[41]$} \\
\hline
\end{tabular}




\begin{tabular}{cccc}
\hline MWCNT & Water & 11.3 & {$[42]$} \\
\hline $\mathrm{CuO}$ & Water & 37 & {$[43]$} \\
\hline $\mathrm{ZnO}$ & Water & 21 & {$[44]$} \\
\hline $\mathrm{MgO}$ & Water & 22 & {$[45]$}
\end{tabular}

\section{For $\mathrm{CNT} / \mathrm{Fe}_{3} \mathrm{O}_{4} \mathrm{Hybrid}$ nanofluid $(\mathrm{HN})$}

Figure 12, shows the thermal conductivity enhancement (TCE) of HN. It can be seen that the maximum TCE for MWCNT/ $/ \mathrm{Fe}_{3} \mathrm{O}_{4} /$ Water $\mathrm{HN}$ is about $33.23 \%$ which is at the most volume fraction and temperature [46]. Nanoparticles number and thus, Brownian motion increase at upper temperature and volume fraction. So, TCE percentage of $\mathrm{MN}$ at this state, is more than that at lower temperature.

For $\mathrm{HN} 0.2 \mathrm{Vol} \%$, Thermal conductivity enhancement raised 5.37\% (18.81 to 24.18 from $25^{\circ} \mathrm{C}$ to $\left.50^{\circ} \mathrm{C}\right)$

For $\mathrm{HN} 1.0 \mathrm{Vol} \%$, Thermal conductivity enhancement raised $7.32 \%$ (25.91 to 33.23 from $25^{\circ} \mathrm{C}$ to $\left.50^{\circ} \mathrm{C}\right)$

Which means when volume fraction increased about $0.8 \%$, Thermal conductivity enhancement raised about $1.95 \%$.

Results indicated that by adding MWCNT to $\mathrm{Fe}_{3} \mathrm{O}_{4}$, Thermal conductivity enhanced about $0.47 \%$ [47].

Thermal conductivity enhancement of various particles in HN noticed at Table 4. 


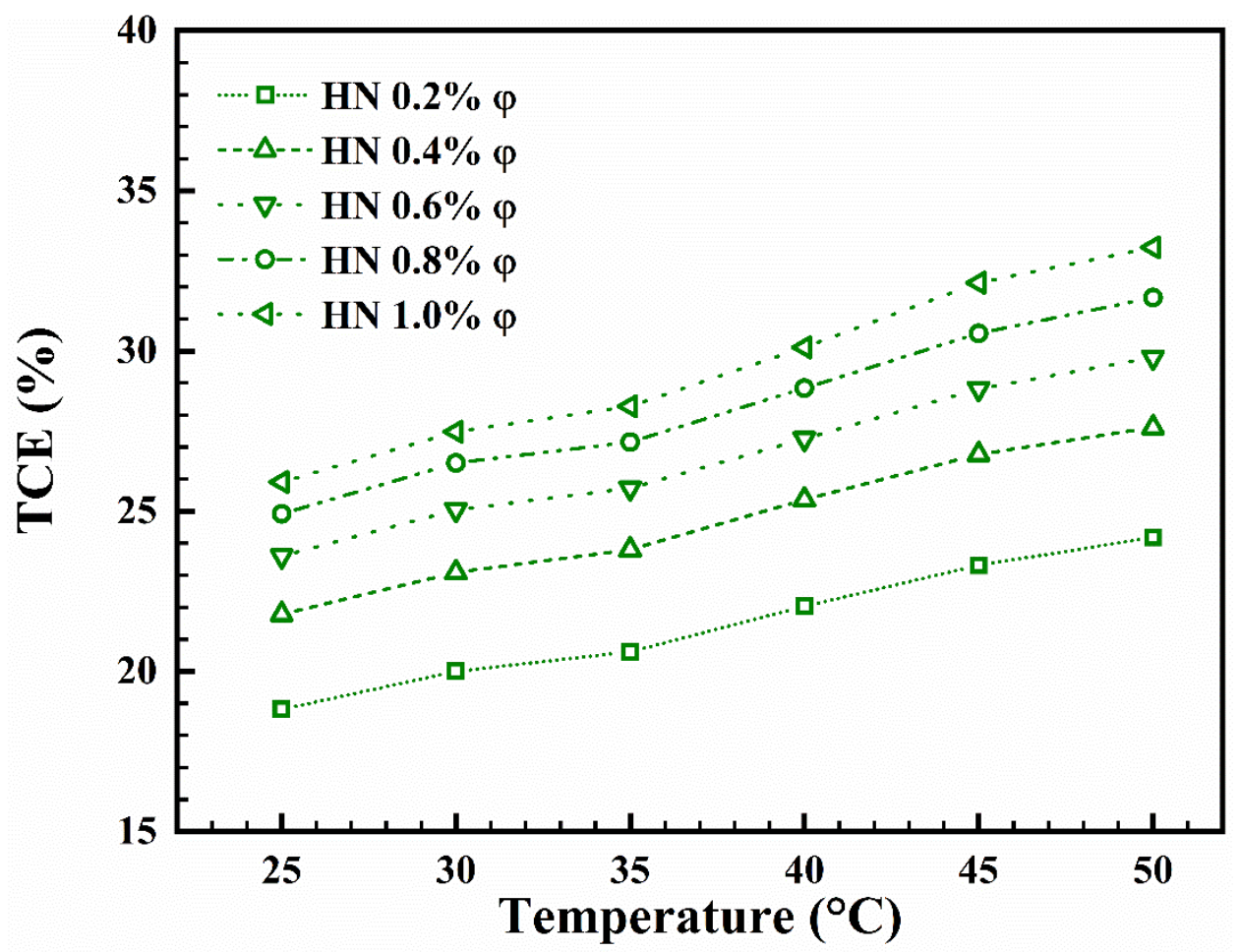

Figure 12. Variations in Thermal conductivity enhancement by nanofluid temperature at different volume fractions

Table 4. Thermal conductivity enhancement of various particles in hybrid nanofluids

\begin{tabular}{cccc}
\hline Dispersed particles & Basefluid & Maximum enhancement/\% & Ref. \\
\hline Fe3O4-MWCNT & Water & $33.23 \% ~ @ 1.0$ vol\% & This Work \\
\hline Ag-MWCNT & Water & 37.3 & {$[48]$} \\
\hline $\begin{array}{c}\text { Nano } \\
\text { Diamond/Nickle }\end{array}$ & Water & 21 & {$[49]$} \\
\hline MWCNT-y Alumina & Water & 20.6 & {$[50]$} \\
\hline Cu-Al2O3 & Water & 13.6 & {$[51]-[53]$} \\
\hline
\end{tabular}

\subsection{Numerical Study}

To present a new correlation with $0.9 \mathrm{R}$-squared, experimental data of thermal conductivity ratio (TCR) in 3-dimentional plotted. Then, Curve-fitting method applied and different types of correlations investigated to find the best fit [54]. 


\section{Correlation for $\mathrm{Fe}_{3} \mathrm{O}_{4}$ mono nanofluid}

A dependable correlation introduced to calculate TCR of $\mathrm{Fe}_{3} \mathrm{O}_{4} /$ Water mono nanofluid. This correlation can be used to calculate TCR at specific range of volume fraction and temperature. Temperature and volume fraction effect on TCR of mono nanofluid is obvious by this equation. Figure 13 displays the fitted correlation on experimental data.

Proposed correlation is presented in Equation 3.

$$
\frac{k_{n f}}{k_{b f}}=1+\left(0.03542 * T^{0.57325 * V^{0.49394}}\right)
$$

Where $T$ is Temperature (in ${ }^{\circ} \mathrm{C}$ ) and $V$ is volume fraction (in \%) of nanofluid.

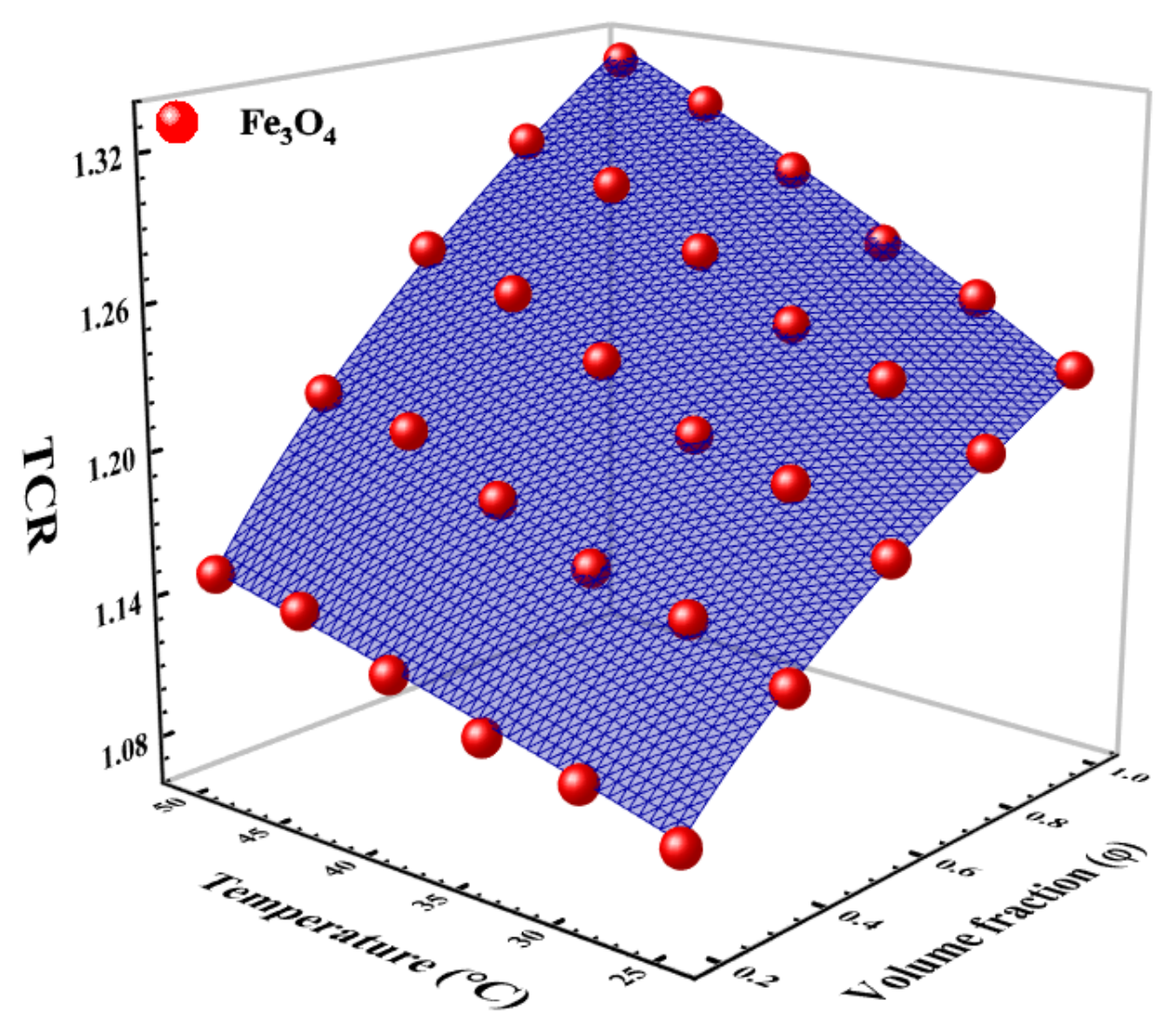

Figure 13. 3D-Applied correlation on thermal conductivity ratio data

Figure 14 displays 6 graphs (for each temperature), to find relation between the experimental results and correlation outputs in all temperatures. This figure, displays TCR by mono nanofluid 
volume fraction in various temperatures. Also, thermal conductivity correlations were reported for various mono nanofluids, presented in Table 5.
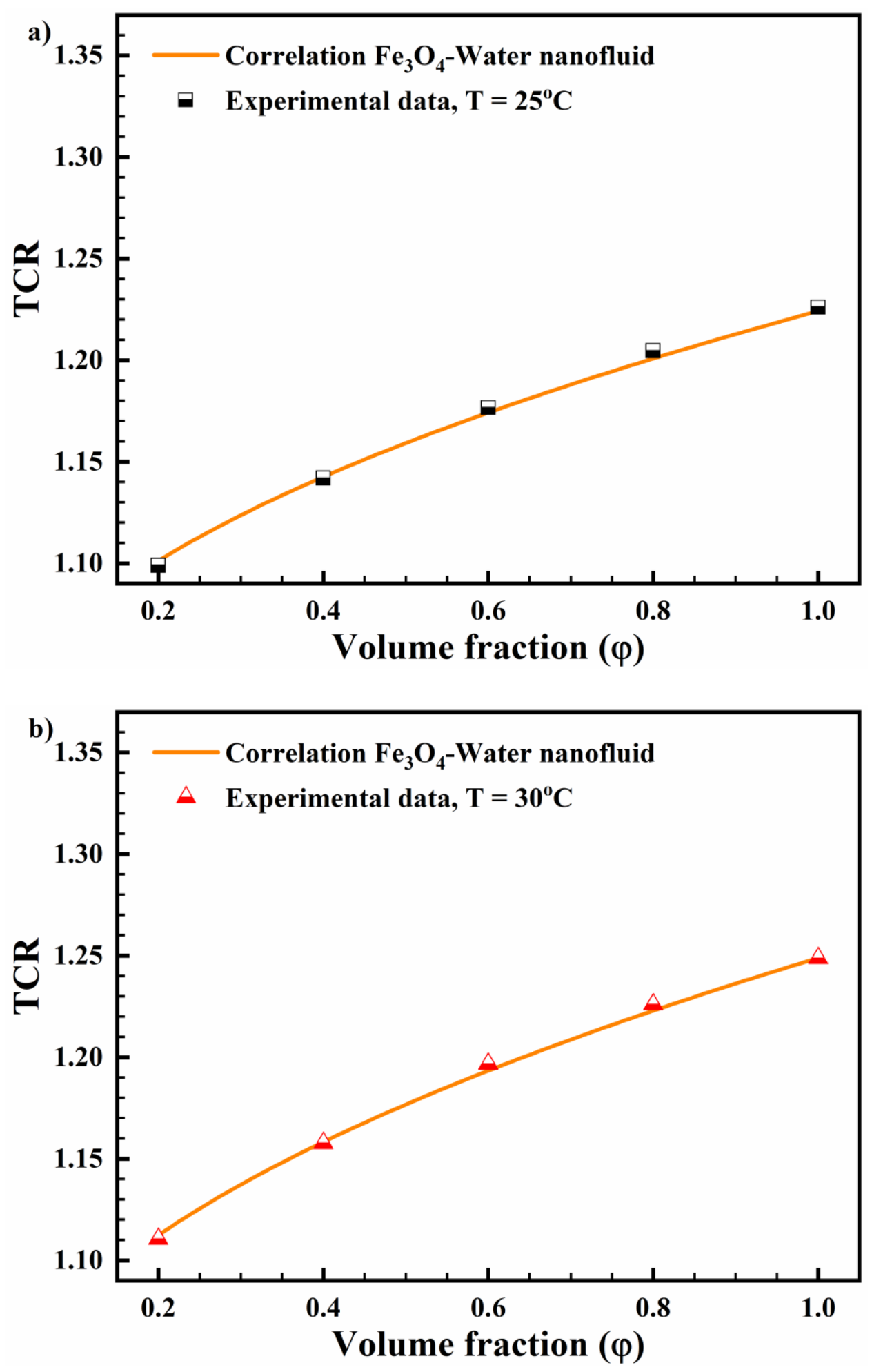

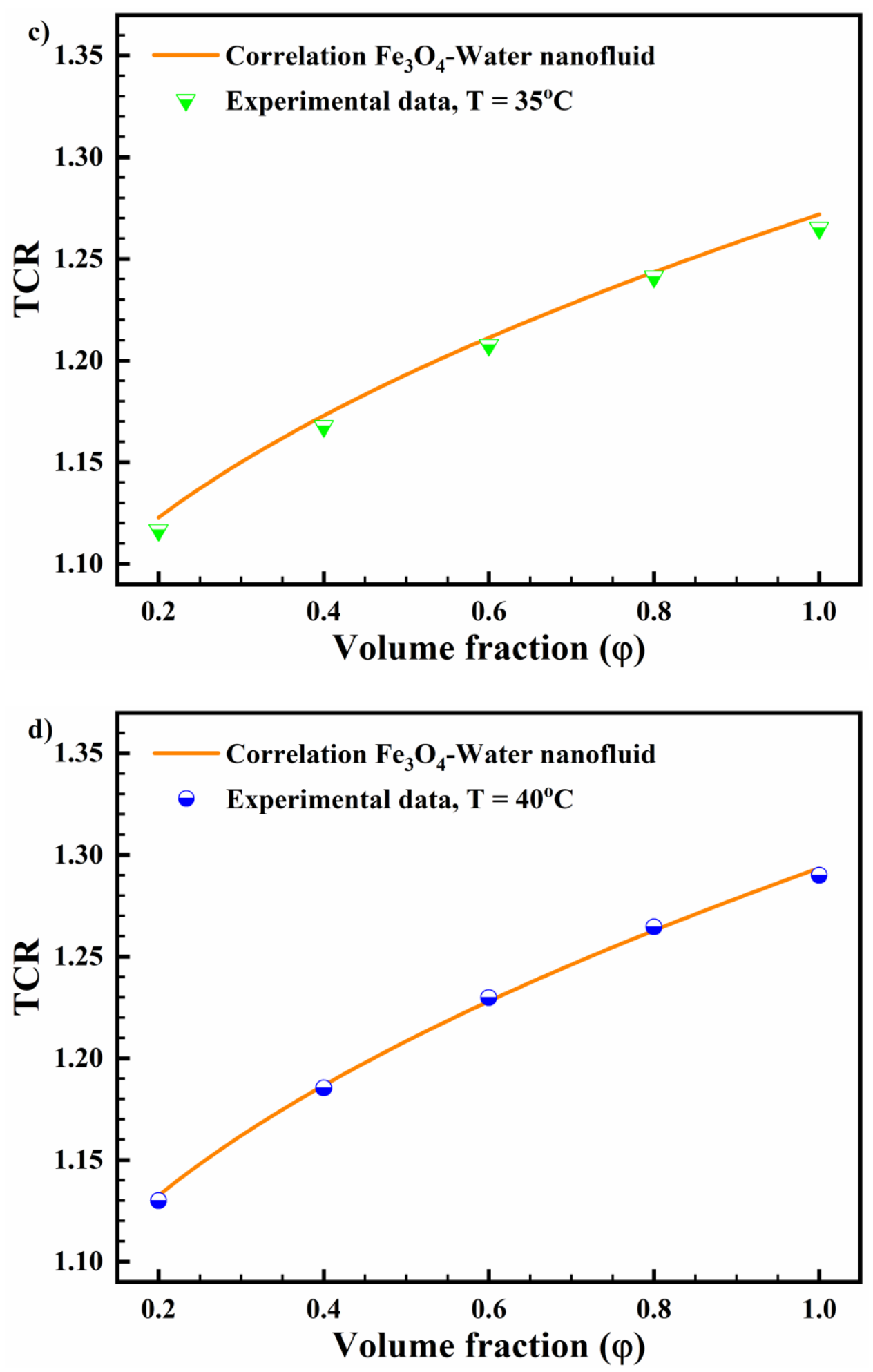

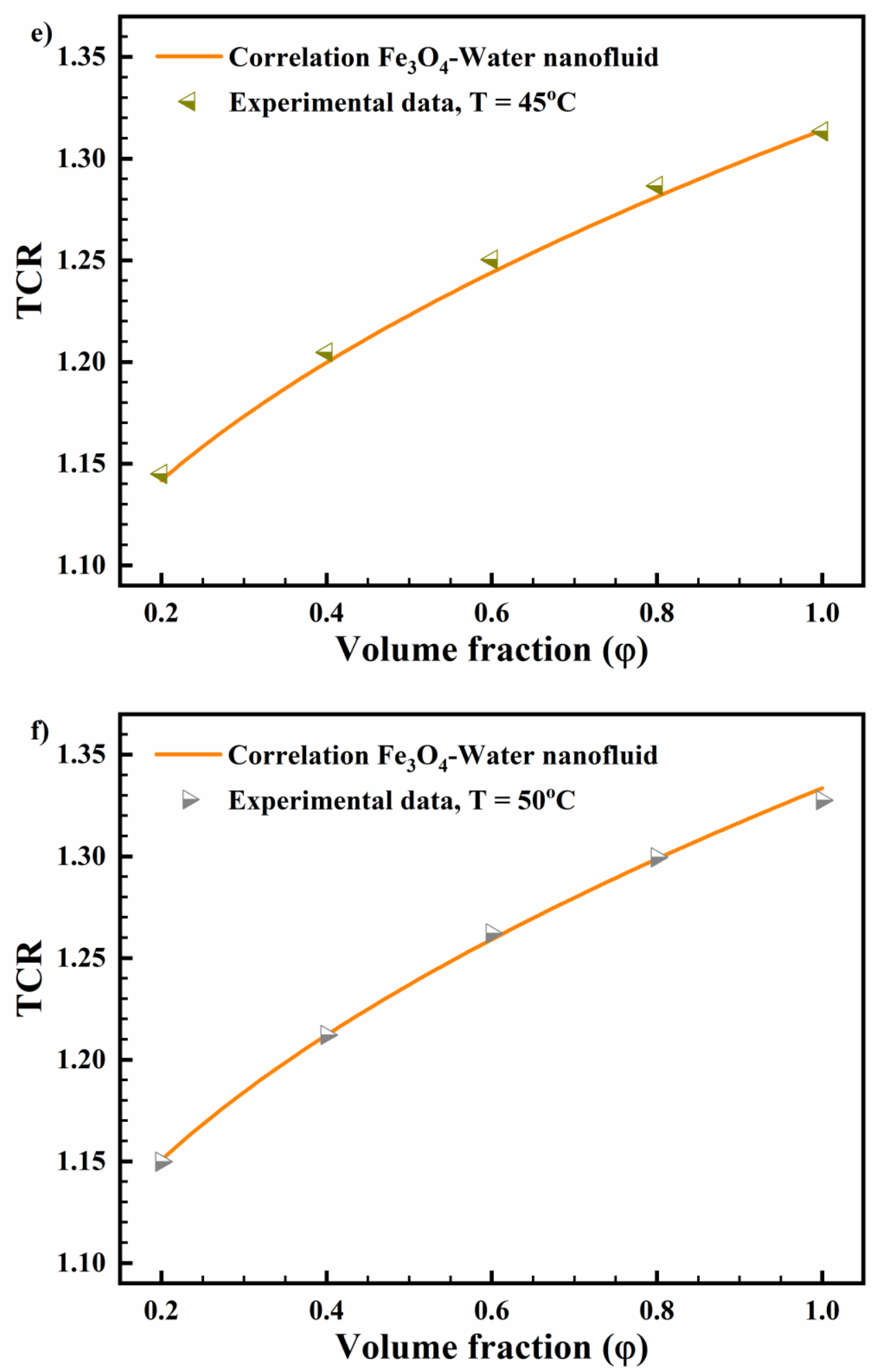

Figure 14. Verify presented method by experimental results regarding to Thermal conductivity ratio by nanofluid volume fraction at different temperatures 
Table 5. Thermal conductivity correlations for various mono nanofluids

\begin{tabular}{ccc}
\hline Nanofluid & Correlation & Ref. \\
\hline $\mathrm{Al}_{2} \mathrm{O}_{3} /$ Water & $\frac{\mathrm{k}_{\mathrm{nf}}-\mathrm{k}_{\mathrm{bf}}}{\mathrm{k}_{\mathrm{bf}}}=0.764481464 u+0.018688867 T-0.462147175$ & [55] \\
\hline $\mathrm{CuO} /$ Water & $\frac{\mathrm{k}_{\mathrm{nf}}-\mathrm{k}_{\mathrm{bf}}}{\mathrm{k}_{\mathrm{bf}}}=3.761088 u+0.017924 T-0.30734$ & [55] \\
\hline $\mathrm{ZnO/EG-Water}$ & $\frac{\mathrm{k}_{\mathrm{nf}}-\mathrm{k}_{\mathrm{bf}}}{\mathrm{k}_{\mathrm{bf}}}=\left(\frac{1.8454-5.2302 \phi^{0.29216}}{T^{0.29216}-3.457}\right) * 100$ & [56] \\
\hline $\begin{array}{c}\text { MWCNT/EG- } \\
\text { Water }\end{array}$ & $\frac{\mathrm{k}_{\mathrm{nf}}}{\mathrm{k}_{\mathrm{bf}}}=0.9212+1.0975 \phi^{0.319} \exp (0.01286 \mathrm{~T})$ & [57] \\
\hline
\end{tabular}

Deviation margin, which can confirm the accuracy of presented correlation, is calculated in equation 4.

Deviation margin $(\%)=\frac{k_{E x p}-k_{\text {Pred }}}{k_{E x p}} \times 100$

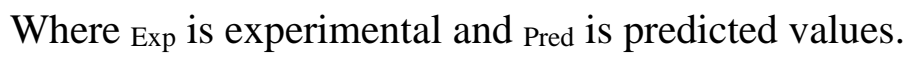

Figure 15 shows an acceptable agreement between experimental data and correlation outputs. Maximum positive and negative deviation margins for this correlation are $0.6007 \%$ and $0.5221 \%$ respectively. Thus, the total deviation margin gap is about $1.1228 \%$. 


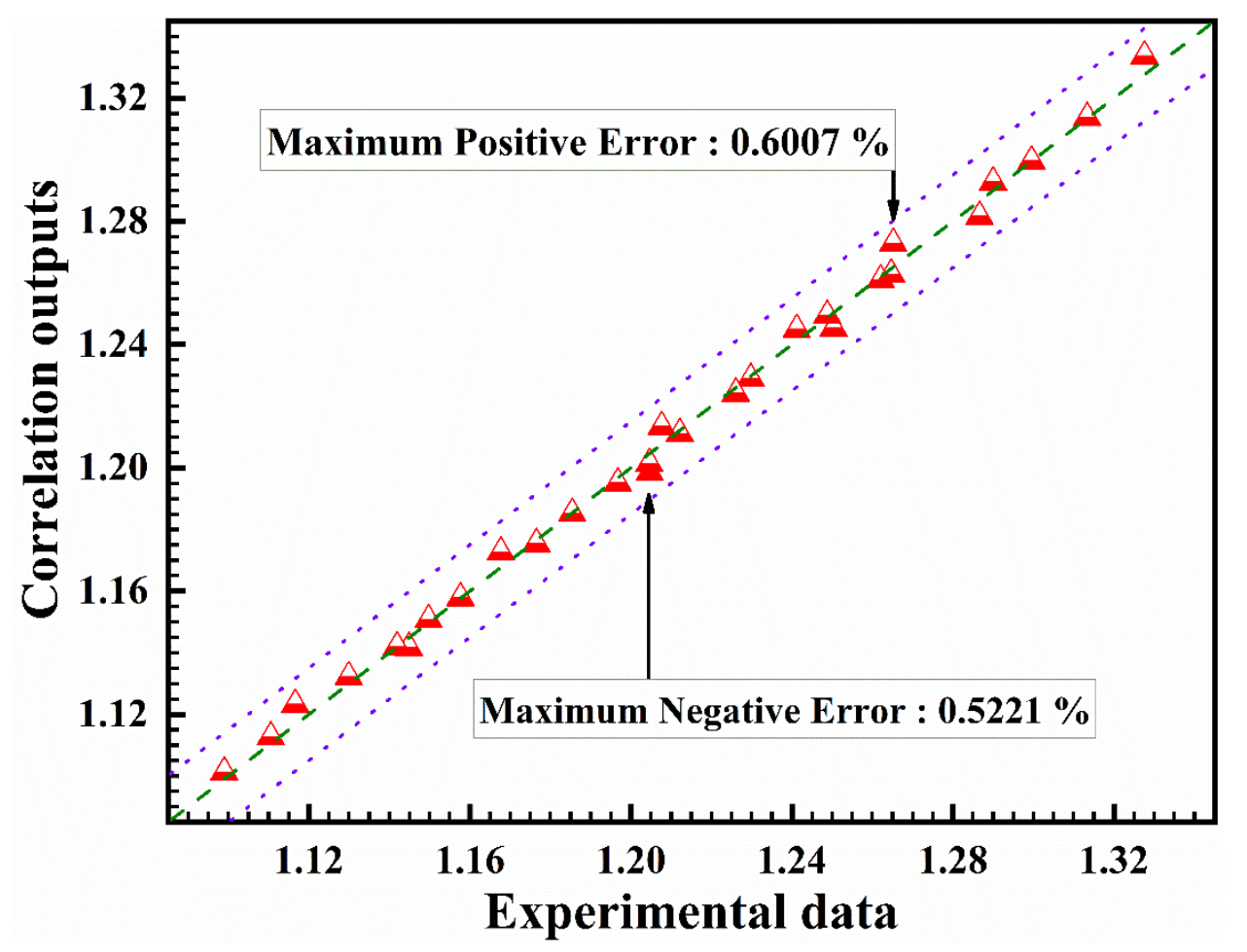

Figure 15. Verify presented method by experimental results

Figure 16 displays margin of deviation by mono nanofluid's volume fraction and also shows comparison between errors of correlation outputs for each temperature. The margin of deviation in this figure calculated by presented correlation. It can be seen that accuracy matter in thermal conductivity predicting [58]. 


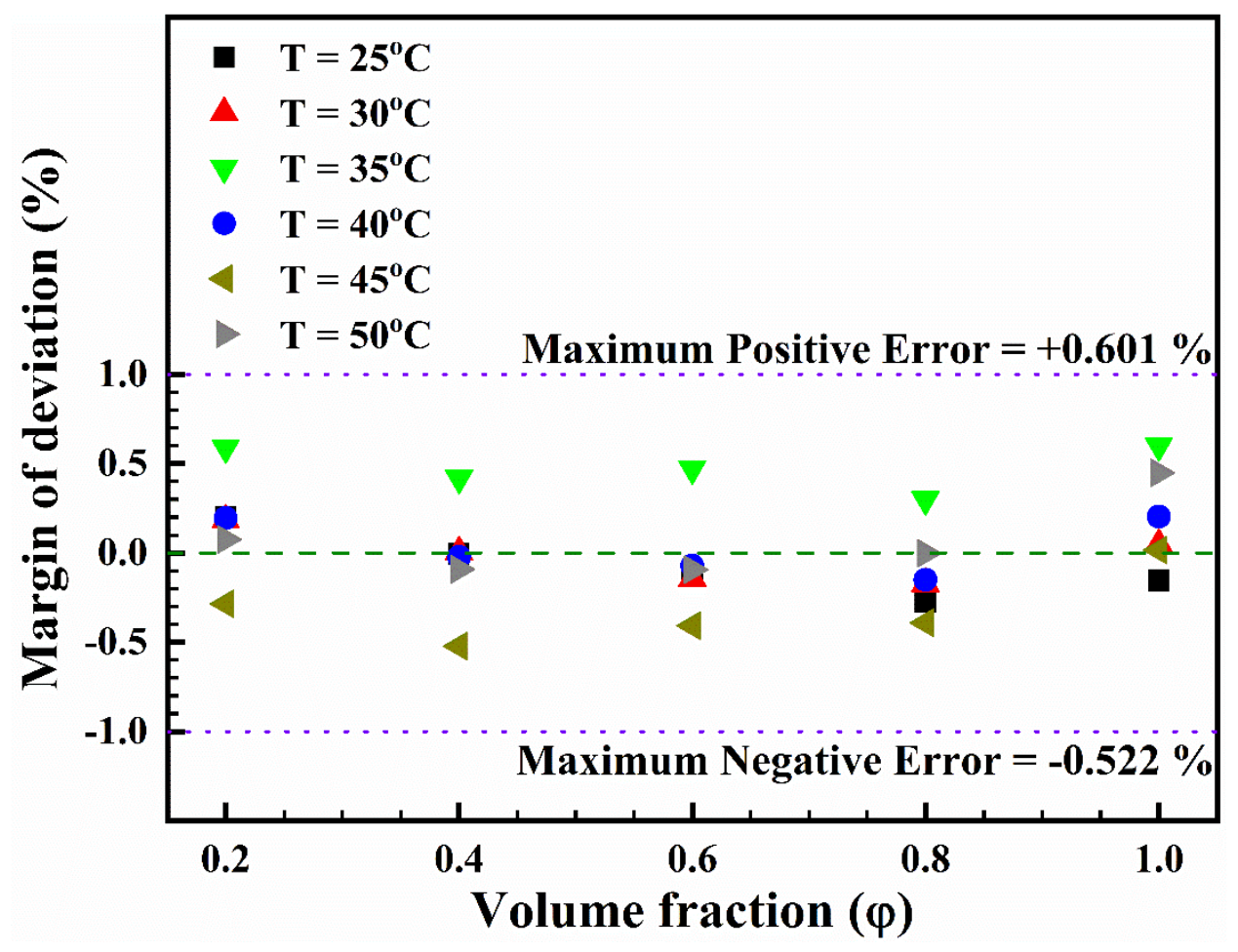

Figure 16. Margin of deviation by nanofluid volume fraction

\section{Correlation for $\mathrm{CNT} / \mathrm{Fe}_{3} \mathrm{O}_{4} \mathrm{Hybrid}$ nanofluid}

A dependable correlation introduced to calculate TCR of $\mathrm{MWCNT} / \mathrm{Fe}_{3} \mathrm{O}_{4} /$ Water hybrid nanofluid. This correlation can be used to calculate TCR at specific range of volume fraction and temperature. Temperature and volume fraction effect on TCR of hybrid nanofluid is obvious by this equation. Figure 17 displays the fitted correlation on experimental data.

Proposed correlation is presented in Equation 5.

$$
\frac{k_{n f}}{k_{b f}}=1+\left(0.08134 * T^{0.35753} * V^{0.19655}\right)
$$

Where $T$ is Temperature (in ${ }^{\circ} \mathrm{C}$ ) and $V$ is volume fraction (in \%) of nanofluid. 


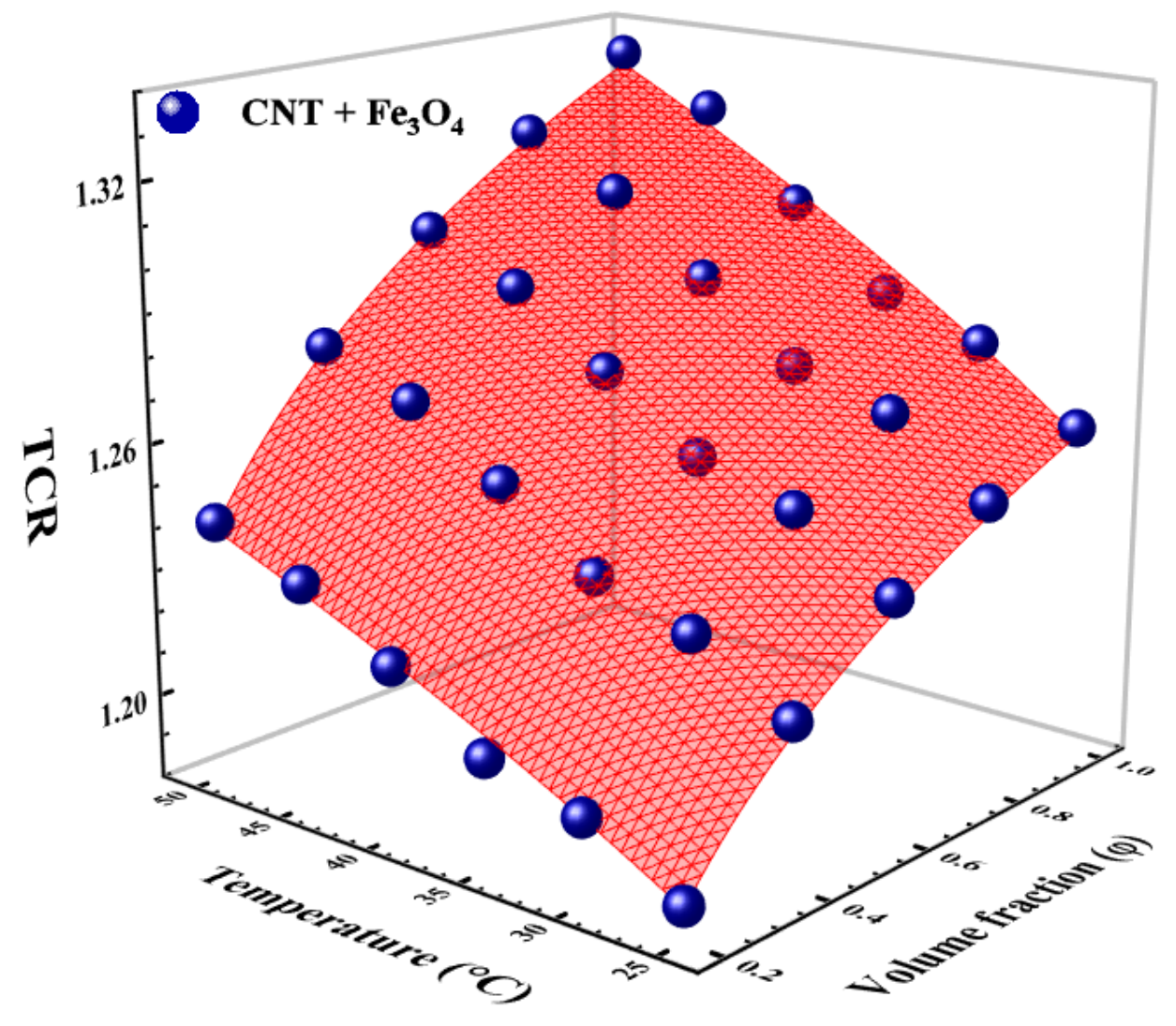

Figure 17. 3D-Applied correlation on thermal conductivity ratio data

Figure 18 displays 6 graphs (for each temperature), to find the relation between the experimental results and correlation outputs in all temperatures. This figure, displays TCR by hybrid nanofluid volume fraction in various temperatures [59]. Also, thermal conductivity correlations were reported for various hybrid nanofluids, presented in Table 6. 

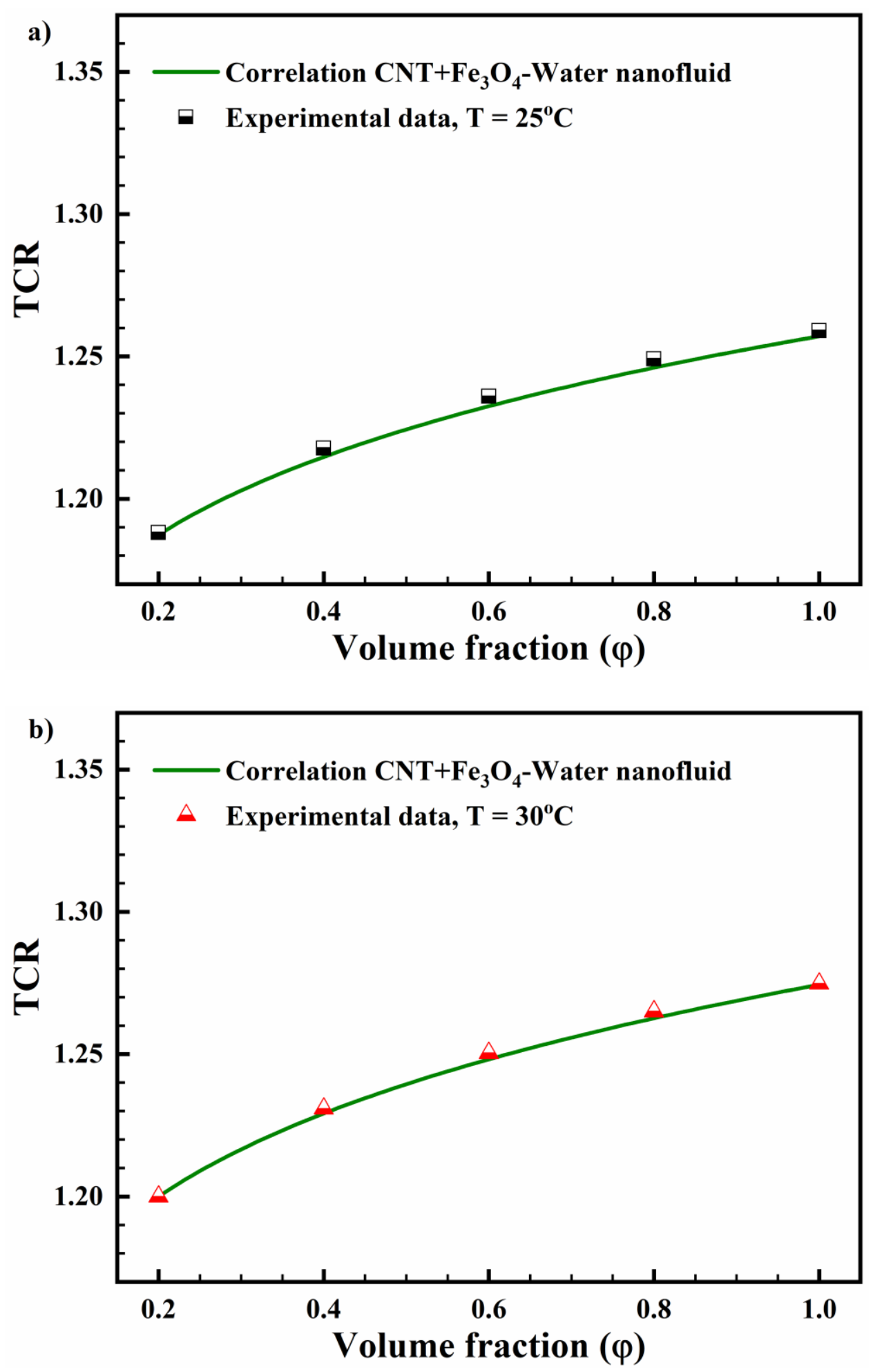

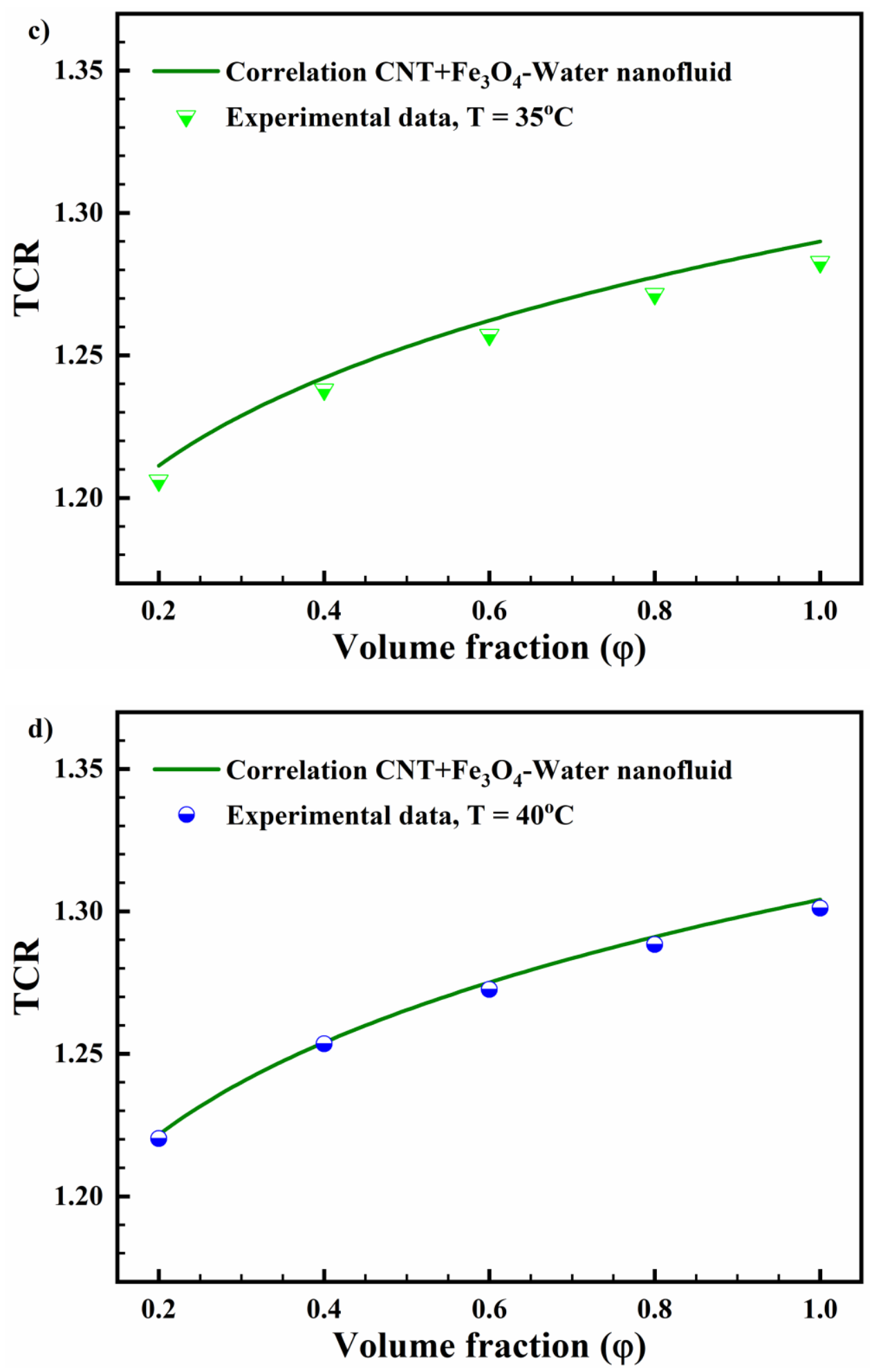

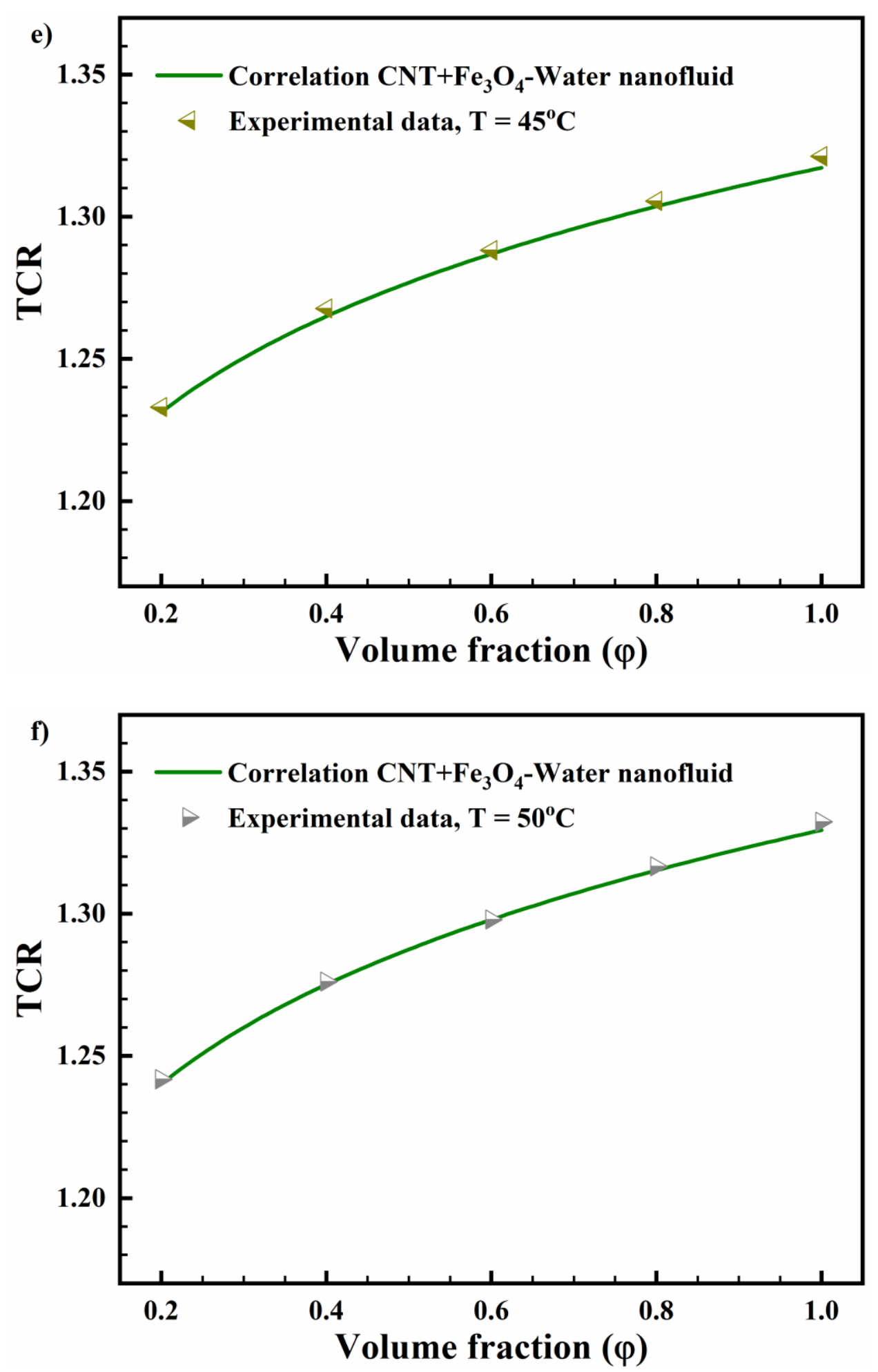

Figure 18. Verify presented method by experimental results regarding to Thermal conductivity ratio by nanofluid volume fraction at different temperatures 
Table 6. Thermal conductivity correlations for various hybrid nanofluids

\begin{tabular}{ccc}
\hline Nanofluid & Correlation & Ref. \\
\hline MWCNT- & $\frac{\mathrm{k}_{\mathrm{nf}}}{\mathrm{TiO}_{2} / \text { EG- }}=0.006 *\left(\phi^{1.099}\right) * T^{1.051}+1.014$ & {$[60]$} \\
Water & $\mathrm{k}_{\mathrm{bf}}$ & \\
\hline
\end{tabular}

Deviation margin, which can confirm the accuracy of presented correlation, is calculated in equation 6.

$$
\text { Deviation margin }(\%)=\frac{k_{E x p-H N}-k_{\text {Pred }-H N}}{k_{E x p-H N}} \times 100
$$

Where Exp-HN is hybrid nanofluid's experimental and Pred-HN is hybrid nanofluid's predicted values [61].

Figure 19 shows an acceptable agreement between experimental data and correlation outputs. Maximum positive and negative deviation margins for this correlation are $0.6096 \%$ and $0.3247 \%$ respectively. Thus, the total deviation margin gap is about $0.9343 \%$.

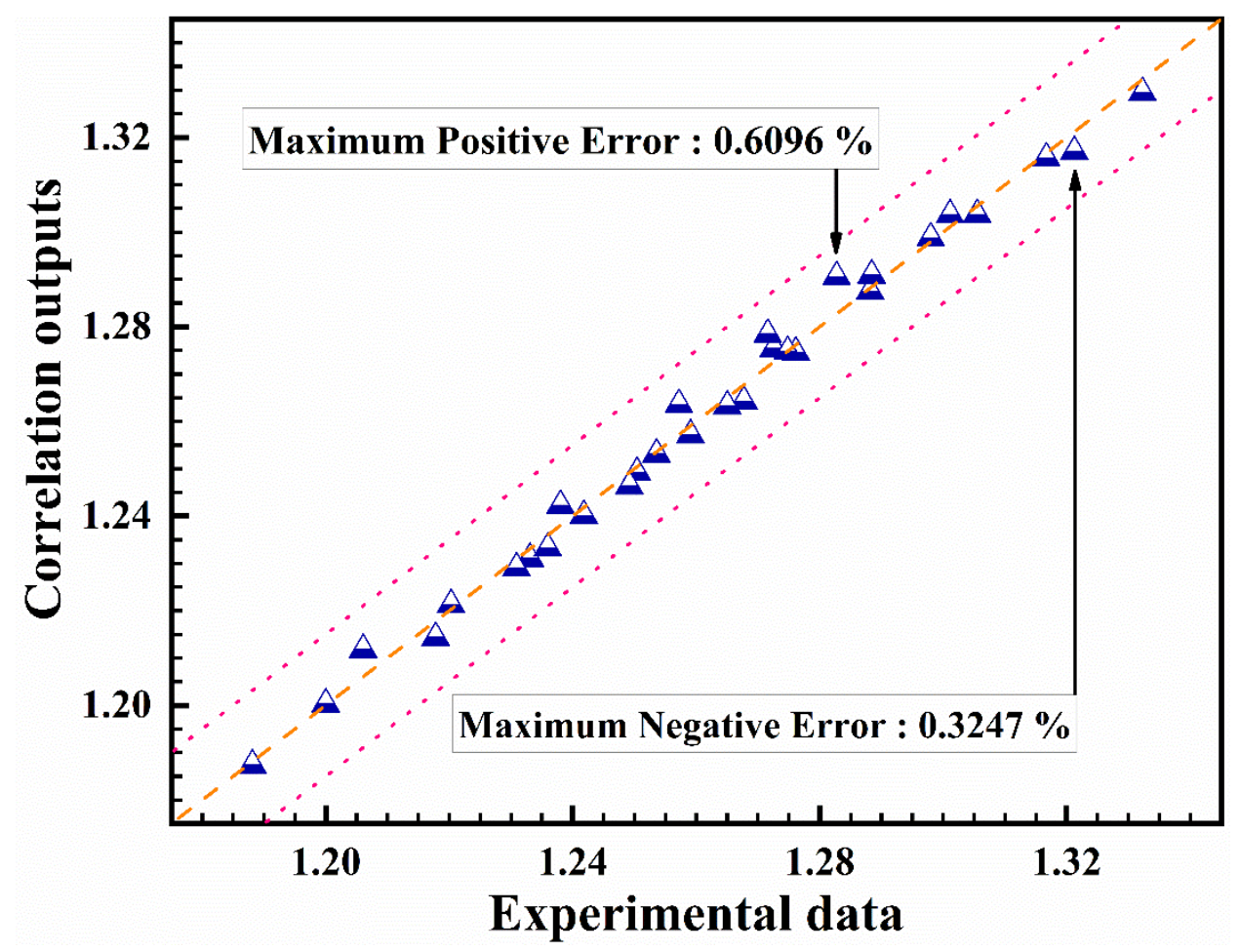

Figure 19. Verify presented method by experimental results 
Figure 20 displays margin of deviation by hybrid nanofluid's volume fraction and also shows comparison between errors of correlation outputs for each temperature. The margin of deviation in this figure was calculated by presented correlation. It can be seen that accuracy matter in thermal conductivity predicting.

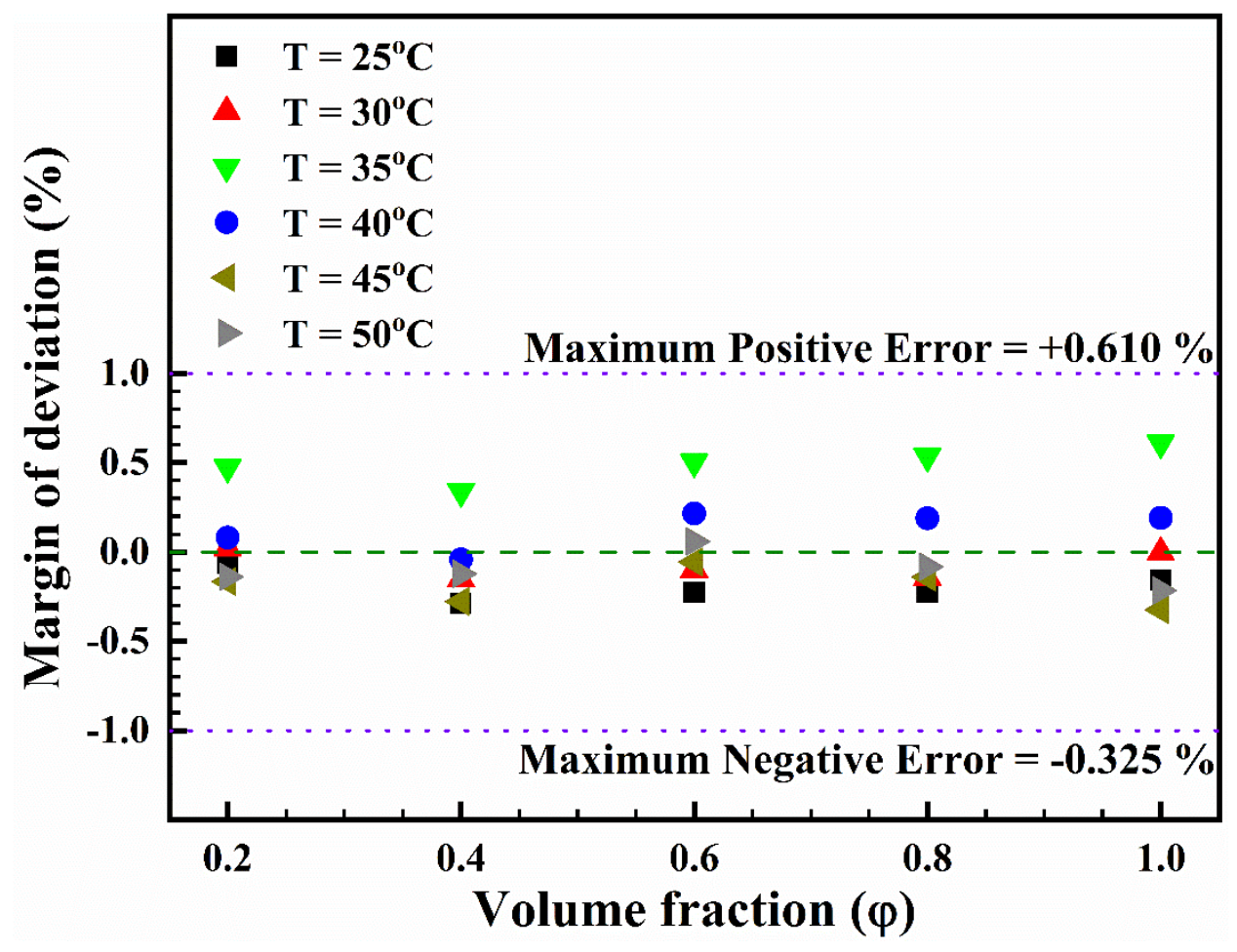

Figure 20. Margin of deviation by nanofluid volume fraction

\section{Artificial Neural Network}

In this paper, the experimental data was measured. After that, an algorithm was proposed to determine the best neuron number in the hidden layer. By using curve-fitting method, the ANN outputs were compared to experimental results [62]. Thermal conductivity was predicted by ANN based on the volume fraction and temperature. 100 Data points (divided into test, validation and train categories) were set. 15 data considered as test, 15 data for validation and 70 data points were considered as train data. While Train data was used in training the ANN, validation data monitors and modifies the training process. Also, the test data points were used to evaluate the accuracy and reliability of ANN. To model ANN, thermal conductivity considered as output and nanoparticle temperature-volume fractions considered as input. Thus, Levenberg-Marquardt backpropagation 
algorithm is used and a general two-layer, feed-forward network with 20 sigmoid hidden neurons and linear output neurons trained [63].

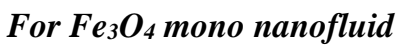

$\mathrm{Fe}_{3} \mathrm{O}_{4} /$ Water mono nanofluid's thermal properties can be predicted by an Artificial Neural Network (ANN) model. Figure 21 shows a color fill contour for trained data and experimental data. With 30 experimental data, lines in Figure 21.a are wavy, however, with 1000 trained data (estimated from ANN model), lines are smooth in Figure 21.b.

a)

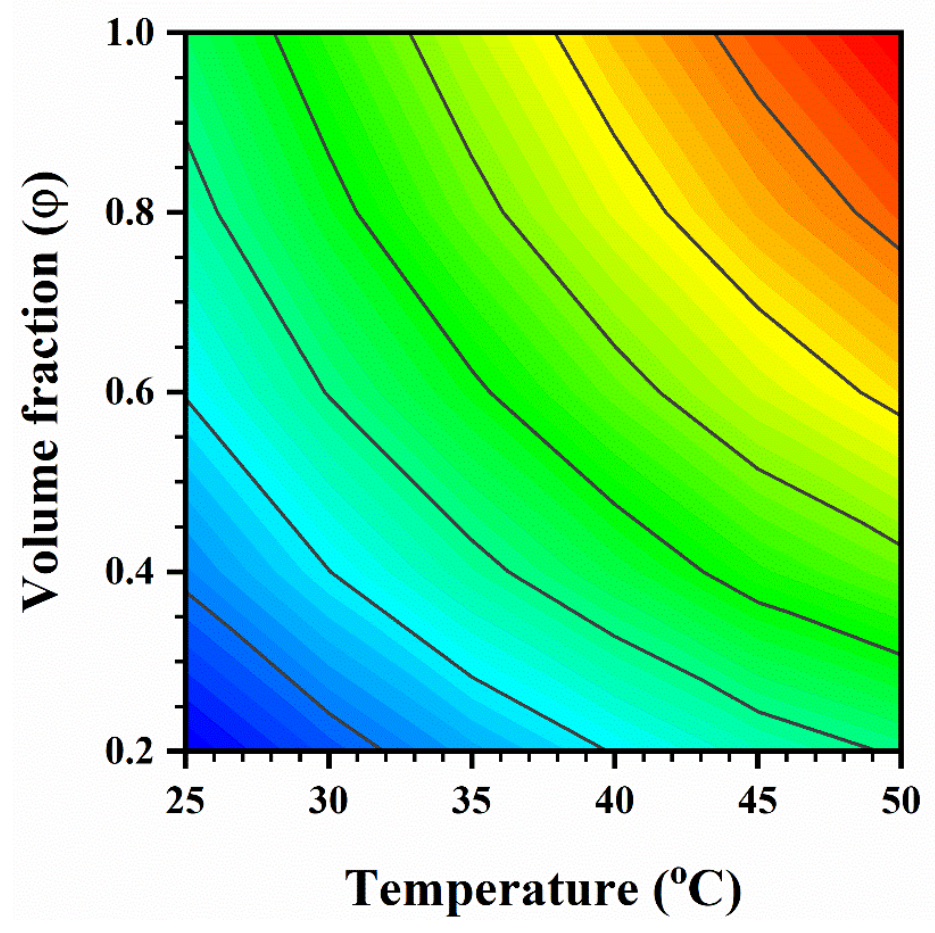

TC (W/m.K)

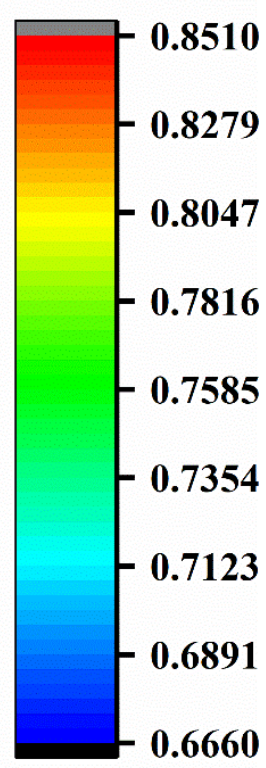


b)

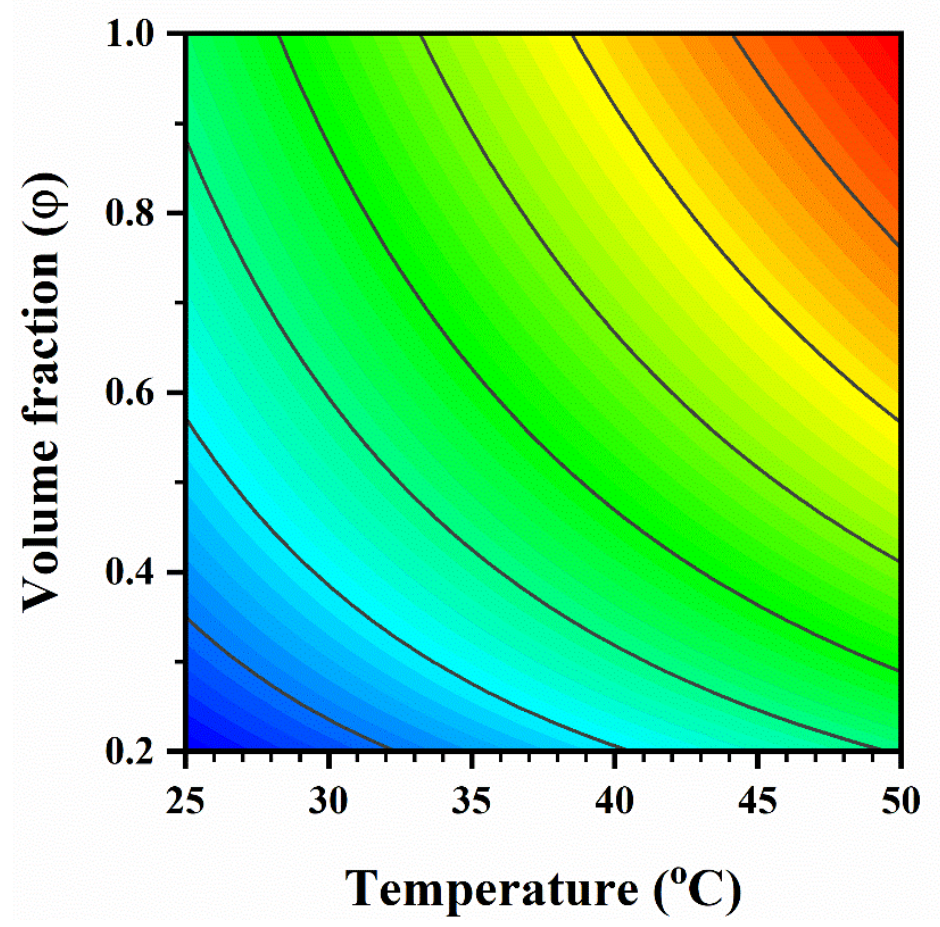

TC $(\mathbf{W} / \mathbf{m} . K)$

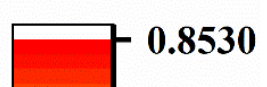

0.8296

0.8061

0.7827

0.7592

0.7358

0.7124

0.6889

0.6655

Figure 21. Contour - Color fill of (a) main data and (b) trained data

Figure 22 shows an acceptable agreement between experimental data and trained model outputs. Maximum positive and negative deviation margins for this model are $0.5862 \%$ and $0.3987 \%$ which are $0.0145 \%$ and $0.1234 \%$ less than maximum deviation margin of presented correlation. Also, the total deviation margin gap is about $0.9849 \%$ which is $0.1379 \%$ less than correlation [64]. 


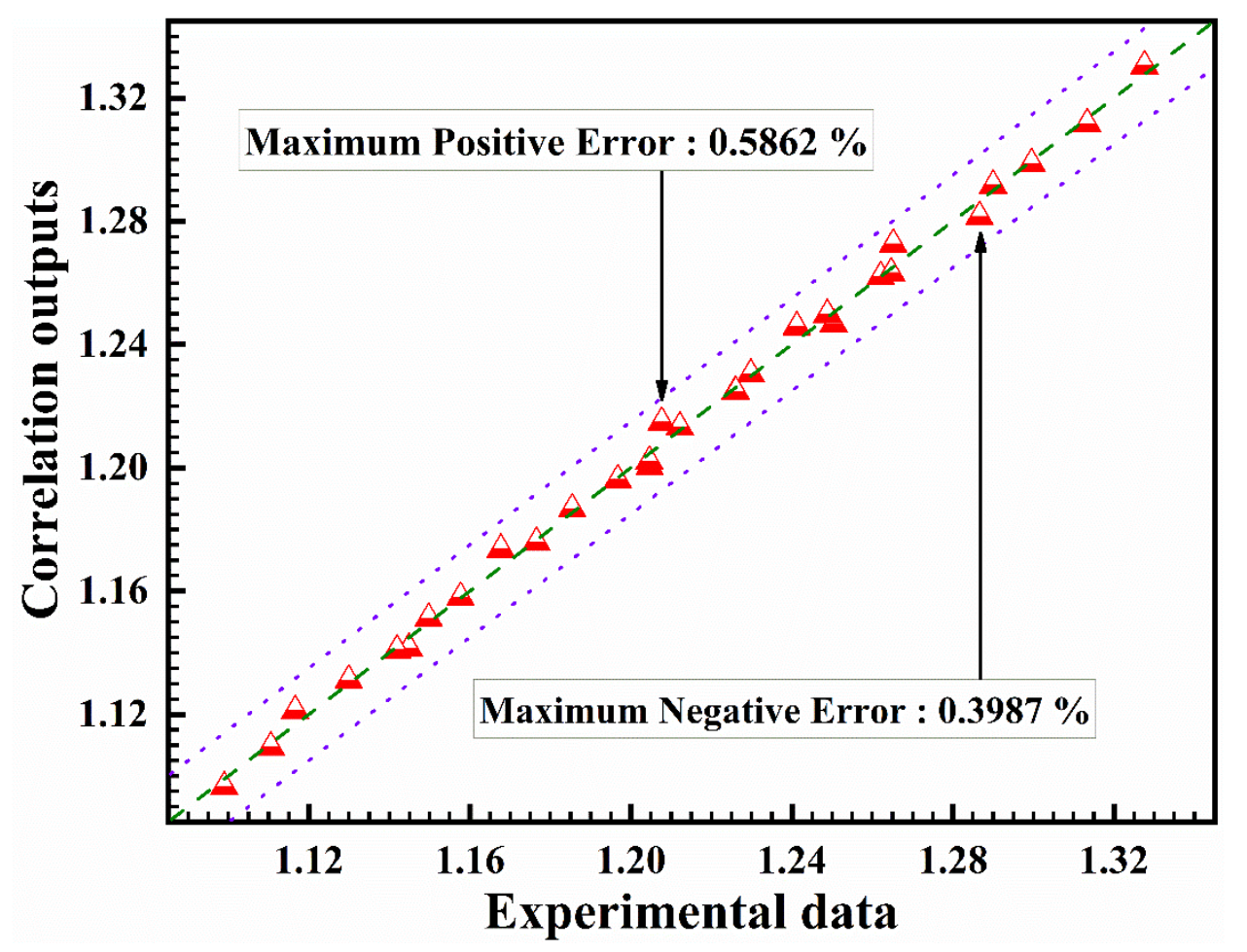

Figure 22. Verify trained data by experimental results

\section{For $\mathrm{CNT} / \mathrm{Fe}_{3} \mathrm{O}_{4} \mathrm{Hybrid}$ nanofluid}

MWCNT/ $/ \mathrm{Fe}_{3} \mathrm{O}_{4} /$ Water mono nanofluid's thermal properties can be predicted by an Artificial Neural Network (ANN) model [65]. Figure 23 shows a color fill contour for the trained data and experimental data. With 30 experimental data, lines in Figure 23.a are wavy, however, with 1000 trained data (estimated from ANN model), lines are smooth in Figure 23.b. 
a)

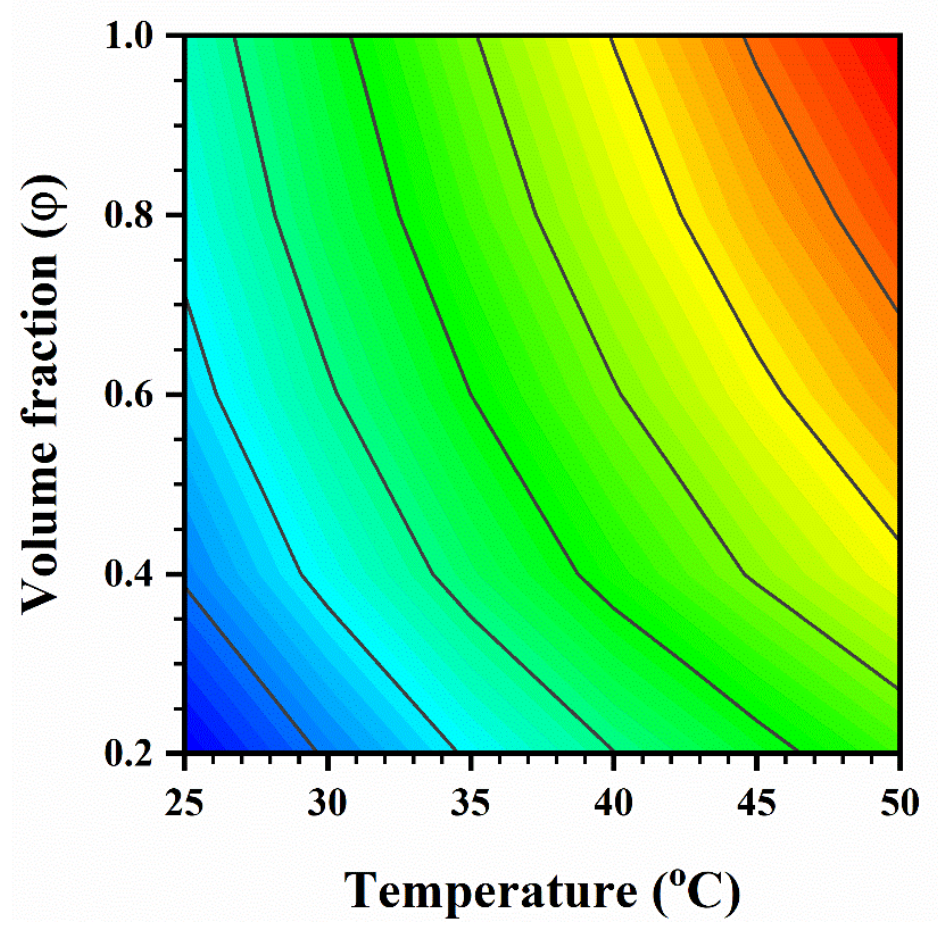

b)

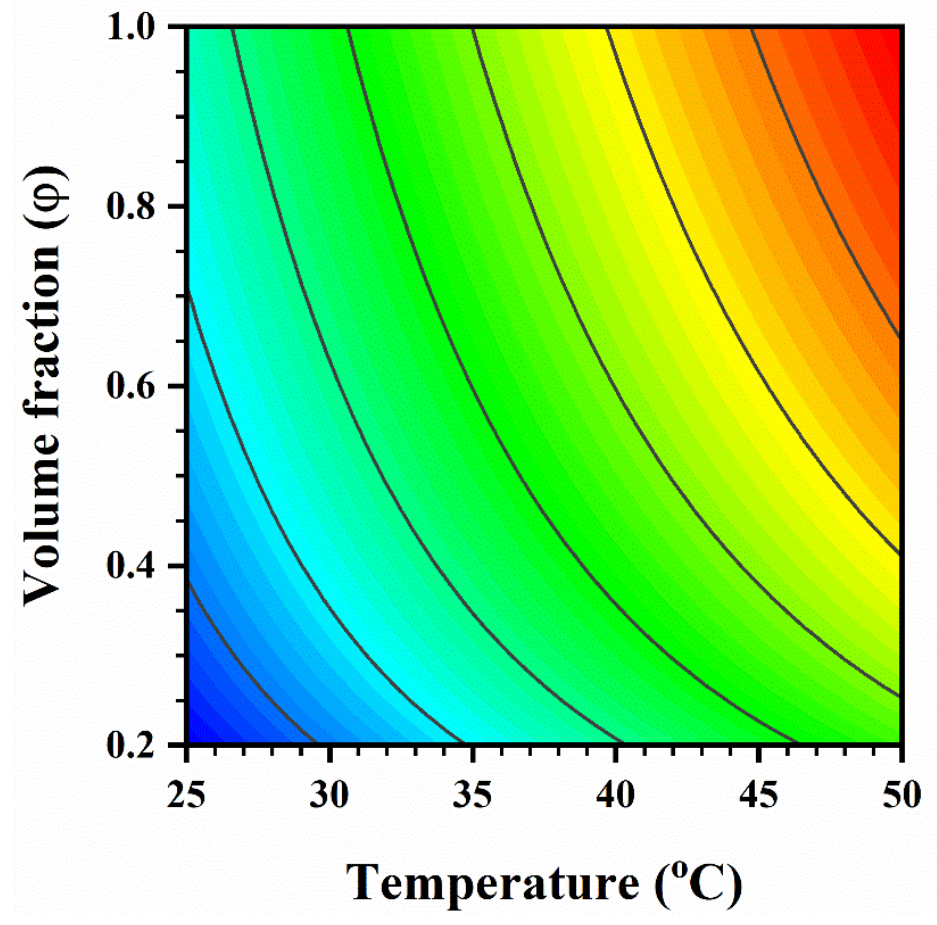

$\mathrm{TC}(\mathrm{W} / \mathbf{m} . \mathrm{K})$

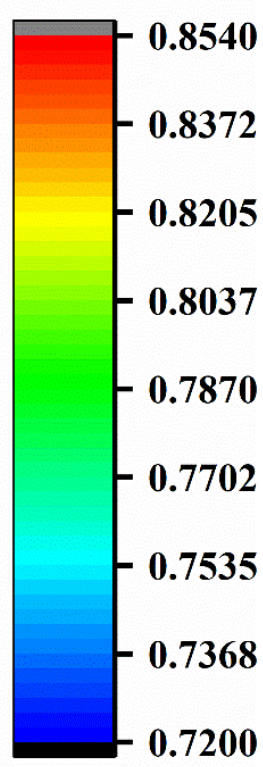

\section{TC $(\mathbf{W} / \mathbf{m} . \mathbf{K})$}

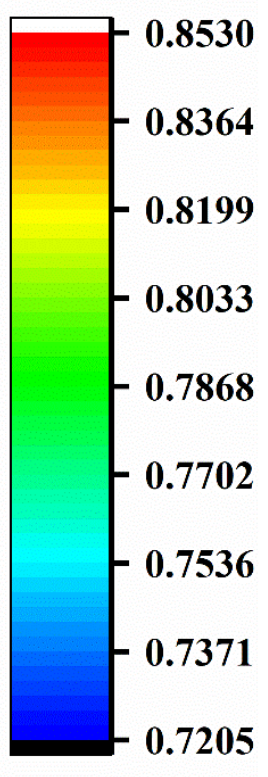

Figure 23. Contour - Color fill of (a) main data and (b) trained data 
Figure 22 shows an acceptable agreement between experimental data and trained model outputs. Maximum positive and negative deviation margins for this model are $0.6057 \%$ and $0.3139 \%$ which are $0.0039 \%$ and $0.0108 \%$ less than maximum deviation margin of the presented correlation. Also, the total deviation margin gap is about $0.9196 \%$ which is $0.0147 \%$ less than correlation [66].

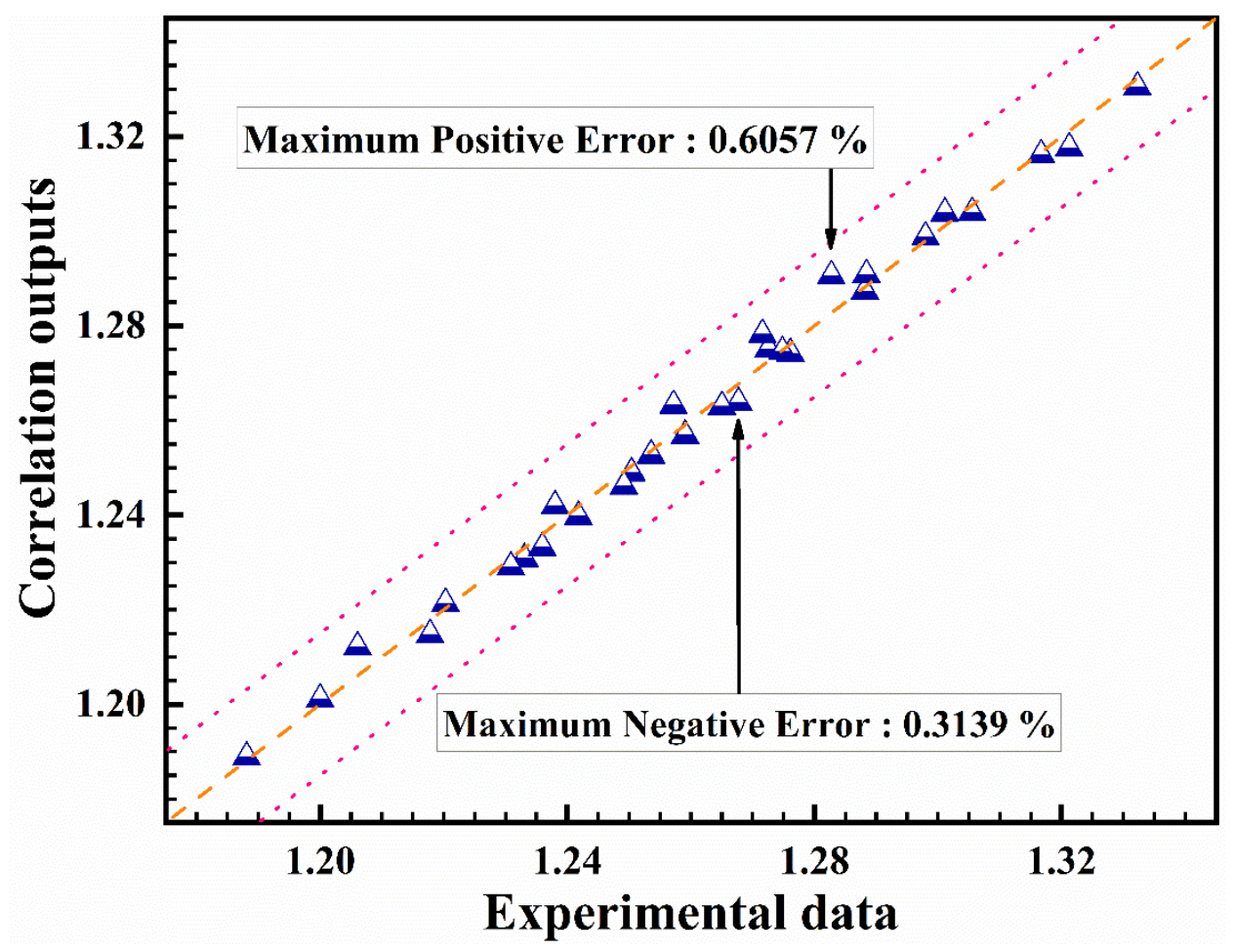

Figure 24. Verify trained data by experimental results

\section{Conclusion}

In this research, multi-walled carbon nanotube (MWCNT) was added to Iron (III) Oxide $\left(\mathrm{Fe}_{3} \mathrm{O}_{4}\right)$ / Water nanofluid to measure enhanced thermal conductivity. So, to improve the Water (base fluid) thermo properties, mono nanofluid (MN) and hybrid nanofluid (HN) prepared solely. For thermal conductivity measurements, $\mathrm{MN}$ and $\mathrm{HN}$ volume fraction ranges were $0.2,0.4,0.6,0.8$ and $1.0 \%$. Also, temperature ranges were $25,30,35,40,45$ and $50^{\circ} \mathrm{C}$. Then, new correlations for $\mathrm{MN}$ and $\mathrm{HN}$ have been calculated by using curve-fitting method on experimental data. These correlations, can calculate $\mathrm{Fe}_{3} \mathrm{O}_{4} /$ Water and MWCNT (50\%) $/ \mathrm{Fe}_{3} \mathrm{O}_{4}(50 \%) /$ Water thermal conductivity in another research. Also, Artificial neural network (ANN) has been modeled for both MN and HN. At the end, calculated data (which obtained by correlation or trained model) was compared with 
experimental data which shows a high accuracy [67]. Thus, ANN models which trained in this research, can predict thermal conductivity properties with acceptable error.

The main results include:

- After dispersing mono $\mathrm{Fe}_{3} \mathrm{O}_{4}$ and hybrid $\mathrm{MWCNT} / \mathrm{Fe}_{3} \mathrm{O}_{4}$ to water, homogeneous and durable nanofluid (for more than $2 \frac{1 / 2}{2}$ months) have been made.

- Thermal conductivity of $\mathrm{MN}$ and $\mathrm{HN}$ were measured at volume fraction ranges up to $1.0 \%$ and temperature ranges up to $50^{\circ} \mathrm{C}$.

- By adding $\mathrm{MWCNT} / \mathrm{Fe}_{3} \mathrm{O}_{4}$, basefluid's thermal conductivity improved and raised by increasing in temperature and volume fraction.

- Maximum thermal conductivity enhancements (TCE) of $32.76 \%$ and $33.23 \%$, were measured at $1.0 \%$ volume fraction and $50^{\circ} \mathrm{C}$ temperature for $\mathrm{MN}$ and $\mathrm{HN}$, individually. These results showed that by adding MWCNT to $\mathrm{Fe}_{3} \mathrm{O}_{4}$, TCE increased about $0.47 \%$.

- $\quad 0.6007 \%$ and $0.6096 \%$ deviations were calculated for $\mathrm{MN}$ and $\mathrm{HN}$ at presented correlations with $\mathrm{R}^{2}=0.9$, individually.

- $\quad 0.5862 \%$ and $0.6057 \%$ deviations were calculated for MN and HN at trained models with $\mathrm{R}^{2}=0.999$, individually

\section{Conflicts of Interest}

There is no conflict of interest.

\section{References}

[1] A. Nasiri, M. Shariaty-Niasar, A. M. Rashidi, and R. Khodafarin, "Effect of CNT structures on thermal conductivity and stability of nanofluid," Int. J. Heat Mass Transf., vol. 55, no. 5-6, pp. 1529-1535, 2012.

[2] L. Chen, H. Xie, Y. Li, and W. Yu, "Nanofluids containing carbon nanotubes treated by mechanochemical reaction," Thermochim. Acta, vol. 477, no. 1-2, pp. 21-24, Oct. 2008. 
[3] H. Jiang, Q. Zhang, and L. Shi, "Effective thermal conductivity of carbon nanotube-based nanofluid,” J. Taiwan Inst. Chem. Eng., vol. 55, pp. 76-81, Oct. 2015.

[4] A. Ahmadi Nadooshan, H. Eshgarf, and M. Afrand, "Measuring the viscosity of Fe3O4MWCNTs/EG hybrid nanofluid for evaluation of thermal efficiency: Newtonian and nonNewtonian behavior,” J. Mol. Liq., vol. 253, no. 2017, pp. 169-177, Mar. 2018.

[5] L. Syam Sundar, M. K. Singh, and A. C. M. Sousa, "Investigation of thermal conductivity and viscosity of Fe3O4 nanofluid for heat transfer applications," Int. Commun. Heat Mass Transf., vol. 44, pp. 7-14, May 2013.

[6] S. Sarbolookzadeh Harandi, A. Karimipour, M. Afrand, M. Akbari, and A. D’Orazio, “An experimental study on thermal conductivity of F-MWCNTs-Fe 3 O 4 /EG hybrid nanofluid: Effects of temperature and concentration," Int. Commun. Heat Mass Transf., vol. 76, pp. 171-177, Aug. 2016.

[7] M. Bahiraei and M. Hangi, “An empirical study to develop temperature-dependent models for thermal conductivity and viscosity of water-Fe3O4 magnetic nanofluid," Mater. Chem. Phys., vol. 181, pp. 333-343, 2016.

[8] M. Akhilesh, K. Santarao, and M. V. S. Babu, "Thermal conductivity of CNT - Wated nanofluids: A review," Mech. Mech. Eng., vol. 22, no. 1, pp. 207-220, 2018.

[9] R. M. Sarviya and V. Fuskele, "Review on Thermal Conductivity of Nanofluids," Mater. Today Proc., vol. 4, no. 2, pp. 4022-4031, 2017.

[10] M. U. Sajid and H. M. Ali, "Thermal conductivity of hybrid nanofluids: A critical review," Int. J. Heat Mass Transf., vol. 126, pp. 211-234, Nov. 2018.

[11] M. H. Ahmadi, A. Mirlohi, M. Alhuyi Nazari, and R. Ghasempour, "A review of thermal conductivity of various nanofluids," J. Mol. Liq., vol. 265, no. 2017, pp. 181-188, Sep. 2018.

[12] M. H. Esfe and M. Afrand, "An updated review on the nanofluids characteristics," $J$. Therm. Anal. Calorim., vol. 138, no. 6, pp. 4091-4101, Dec. 2019.

[13] M. M. Tawfik, "Experimental studies of nanofluid thermal conductivity enhancement and 
applications: A review," Renew. Sustain. Energy Rev., vol. 75, no. July 2016, pp. 12391253, Aug. 2017.

[14] W. I. Liu et al., "A novel comprehensive experimental study concerned graphene oxide nanoparticles dispersed in water: Synthesise, characterisation, thermal conductivity measurement and present a new approach of RLSF neural network," Int. Commun. Heat Mass Transf., vol. 109, p. 104333, Dec. 2019.

[15] S.-R. Yan, R. Kalbasi, Q. Nguyen, and A. Karimipour, "Rheological behavior of hybrid MWCNTs-TiO2/EG nanofluid: A comprehensive modeling and experimental study," $J$. Mol. Liq., p. 113058, Apr. 2020.

[16] M. Niknejadi, M. Afrand, A. Karimipour, A. Shahsavar, and A. H. Meghdadi Isfahani, "Experimental investigation of the hydrothermal aspects of water-Fe3O4 nanofluid inside a twisted tube," J. Therm. Anal. Calorim., no. 0123456789, 2020.

[17] M. Hemmat Esfe, K. Motahari, E. Sanatizadeh, M. Afrand, H. Rostamian, and M. Reza Hassani Ahangar, "Estimation of thermal conductivity of CNTs-water in low temperature by artificial neural network and correlation," Int. Commun. Heat Mass Transf., vol. 76, pp. 376-381, Aug. 2016.

[18] M. H. Esfe, S. Esfandeh, M. K. Amiri, and M. Afrand, "A novel applicable experimental study on the thermal behavior of SWCNTs(60\%)-MgO(40\%)/EG hybrid nanofluid by focusing on the thermal conductivity," Powder Technol., vol. 342, pp. 998-1007, Jan. 2019.

[19] J. H. Lehman, M. Terrones, E. Mansfield, K. E. Hurst, and V. Meunier, "Evaluating the characteristics of multiwall carbon nanotubes," Carbon N. Y., vol. 49, no. 8, pp. 25812602, Jul. 2011.

[20] P. Narayanaswamy Venkatesan and S. Dharmalingam, "Characterization and performance study on chitosan-functionalized multi walled carbon nano tube as separator in microbial fuel cell," J. Memb. Sci., vol. 435, pp. 92-98, 2013.

[21] H. Iida, K. Takayanagi, T. Nakanishi, and T. Osaka, "Synthesis of Fe3O4 nanoparticles with various sizes and magnetic properties by controlled hydrolysis," J. Colloid Interface 
Sci., vol. 314, no. 1, pp. 274-280, 2007.

[22] S. Sedaghat and M. Nasiri, "Linkage of doxycycline onto functionalized multi-walled carbon nano- tube and morphological characterization," vol. 4, no. 4, pp. 203-207, 2015.

[23] A. Baykal, M. Senel, B. Unal, E. Karaoğlu, H. Sözeri, and M. S. Toprak, “Acid Functionalized Multiwall Carbon Nanotube/Magnetite (MWCNT)-COOH/Fe3O4 Hybrid: Synthesis, Characterization and Conductivity Evaluation," J. Inorg. Organomet. Polym. Mater., vol. 23, no. 3, pp. 726-735, 2013.

[24] E. Y. Malikov et al., "Synthesis and characterization of polyvinyl alcohol based multiwalled carbon nanotu be nanocomposites," Phys. E Low-Dimensional Syst. Nanostructures, vol. 61, no. July, pp. 129-134, 2014.

[25] L. Y. Jun, L. S. Yon, N. M. Mubarak, K. S. Yeo, M. Khalid, and C. H. Bing, "Comparison of Drying Method on Acid-functionalized Multi-walled Carbon Nanotube and their Application for Dye Removal,” IOP Conf. Ser. Mater. Sci. Eng., vol. 495, no. 1, 2019.

[26] S. Ebrahimi and S. F. Saghravani, "Experimental study of the thermal conductivity features of the water based $\mathrm{Fe} 3 \mathrm{O} 4 / \mathrm{CuO}$ nanofluid," Heat Mass Transf. und Stoffuebertragung, vol. 54, no. 4, pp. 999-1008, 2018.

[27] ASHRAE, 2015 Ashrae Handbook HVAC applications. 2015.

[28] Y. Geng, H. Khodadadi, A. Karimipour, M. Reza Safaei, and T. K. Nguyen, “A comprehensive presentation on nanoparticles electrical conductivity of nanofluids: Statistical study concerned effects of temperature, nanoparticles type and solid volume concentration," Phys. A Stat. Mech. its Appl., vol. 542, 2020.

[29] A. Asadi, I. M. Alarifi, V. Ali, and H. M. Nguyen, "An experimental investigation on the effects of ultrasonication time on stability and thermal conductivity of MWCNT-water nanofluid: Finding the optimum ultrasonication time," Ultrason. Sonochem., vol. 58, no. April, 2019.

[30] S. Ebrahimi and S. F. Saghravani, "Influence of magnetic field on the thermal conductivity of the water based mixed Fe3O4/CuO nanofluid," J. Magn. Magn. Mater., vol. 441, pp. 366-373, 2017. 
[31] M. Hemmat Esfe, S. Saedodin, W.-M. Yan, M. Afrand, and N. Sina, "Study on thermal conductivity of water-based nanofluids with hybrid suspensions of CNTs/Al2O3 nanoparticles," J. Therm. Anal. Calorim., vol. 124, no. 1, pp. 455-460, Apr. 2016.

[32] T. X. Phuoc, M. Massoudi, and R. Chen, "Viscosity and thermal conductivity of nanofluids containing multi-walled carbon nanotubes stabilized by chitosan," Int. J. Therm. Sci., vol. 50, no. 1, pp. 12-18, Jan. 2011.

[33] K. Abdul Hamid, W. H. Azmi, R. Mamat, and N. A. Usri, "Thermal conductivity enhancement of TiO2nanofluid in water and ethylene glycol (EG) mixture," Indian J. Pure Appl. Phys., vol. 54, no. 10, pp. 651-655, 2016.

[34] C. L. Altan, A. Elkatmis, M. Yüksel, N. Aslan, and S. Bucak, "Enhancement of thermal conductivity upon application of magnetic field to Fe3O4 nanofluids," J. Appl. Phys., vol. 110, no. 9, 2011.

[35] S. S. Sonawane and V. Juwar, "Optimization of conditions for an enhancement of thermal conductivity and minimization of viscosity of ethylene glycol based Fe3O4 nanofluid," Appl. Therm. Eng., vol. 109, pp. 121-129, Oct. 2016.

[36] A. Ijam, A. Moradi Golsheikh, R. Saidur, and P. Ganesan, “A glycerol-water-based nanofluid containing graphene oxide nanosheets," J. Mater. Sci., vol. 49, no. 17, pp. 5934-5944, Sep. 2014.

[37] M. R. Esfahani, E. M. Languri, and M. R. Nunna, "Effect of particle size and viscosity on thermal conductivity enhancement of graphene oxide nanofluid," Int. Commun. Heat Mass Transf., vol. 76, pp. 308-315, Aug. 2016.

[38] E. Sadeghinezhad et al., "An experimental and numerical investigation of heat transfer enhancement for graphene nanoplatelets nanofluids in turbulent flow conditions," Int. J. Heat Mass Transf., vol. 81, pp. 41-51, Feb. 2015.

[39] S. Sen Gupta et al., "Thermal conductivity enhancement of nanofluids containing graphene nanosheets," J. Appl. Phys., vol. 110, no. 8, p. 084302, Oct. 2011.

[40] C. R. J. Glory, M. Bonetti, M. Helezen, M.M.L. Hermite, "Thermal and electrical conductivities of water-based nanofluids prepared with long multiwalled carbon 
nanotubes," J. Appl. Phys., vol. 103, p. 094309, 2008.

[41] W. A. W. M.J. Assael, C.F. Chen, I. Metaxa, "Thermal conductivity of carbon nanotube suspensions in water,” Int. J. Thermophys., vol. 25, pp. 971-985, 2004.

[42] J. K. L. Y.J. Hwang, Y.C. Ahn, H.S. Shin, C.G. Lee, G.T. Kim, H.S. Park, “Investigation on characteristics of thermal conductivity enhancement of nanofluids," Curr. Appl. Phys., vol. 6, pp. 1068-1071, 2006.

[43] W. R. S.K. Das, N. Putra, P. Thiesen, "Temperature dependence of thermal conductivity enhancement for nanofluids," J. Heat Transf, vol. 125, pp. 567-574, 2003.

[44] R. Y. J. Jeong, C. Li, Y. Kwon, J. Lee, S. Hyung Kim, "Particle shape effect on the viscosity and thermal conductivity of ZnO nanofluids," Int. J. Refrig., vol. 36, pp. 22332241, 2013.

[45] S. S. M. Hemmat Esfe, "Turbulent forced convection heat transfer and thermophysical properties of $\mathrm{MgO}$-water nanofluid with consideration of different nanoparticles diameter, an empirical study," J. Therm. Anal. Calorim., vol. 119, pp. 1205-1213, 2015.

[46] M. Soltanimehr and M. Afrand, "Thermal conductivity enhancement of COOHfunctionalized MWCNTs/ethylene glycol-water nanofluid for application in heating and cooling systems," Appl. Therm. Eng., vol. 105, pp. 716-723, Jul. 2016.

[47] L. F. Chen, M. Cheng, D. J. Yang, and L. Yang, "Enhanced Thermal Conductivity of Nanofluid by Synergistic Effect of Multi-Walled Carbon Nanotubes and $\mathrm{Fe}_{2} \mathrm{O}_{3}$ Nanoparticles,” Appl. Mech. Mater., vol. 548-549, pp. 118-123, Apr. 2014.

[48] S. R. N. Jha, "Thermal conductivity studies of metal dispersed multiwalled carbon nanotubes in water and ethylene glycol based nanofluid," J. Appl. Phys., vol. 106, p. 084317, 2009.

[49] A. C. M. S. L. Syam Sundar, Manoj K. Singh, E. Venkata Ramana, Budhendra Singh, Jose' Gra'cio1, "Enhanced Thermal Conductivity and Viscosity of Nanodiamond-Nickel Nanocomposite Nanofluids," Sci. Reports 4, no. 4039, 2014.

[50] K. A. Saloumeh Mesgari Abbasi, Alimorad Rashidi, Ali Nemati, "No Title," Ceram. Int., 
vol. 39, no. 4, p. 3885, 2013.

[51] M. C. S. Suresh, K.P. Venkitaraj, P. Selvakumar, "No Title," Exp. Therm. Fluid Sci., vol. 38, p. 54, 2012.

[52] M. C. S. Suresh, K.P. Venkitaraj, P. Selvakumar, "No Title," Colloids Surfaces A Physicochem. Eng. Asp., vol. 388, p. 41, 2011.

[53] P. S. and S. Suresh, "No Title," IEEE Trans. Components, Packag. Manuf. Technol., vol. 2, no. 10, p. 1600, 2012.

[54] I. Kazemi, M. Sefid, and M. Afrand, "A novel comparative experimental study on rheological behavior of mono \&amp; hybrid nanofluids concerned graphene and silica nano-powders: Characterization, stability and viscosity measurements," Powder Technol., vol. 366, pp. 216-229, Apr. 2020.

[55] C. H. Chon, K. D. Kihm, S. P. Lee, and S. U. S. Choi, "Empirical correlation finding the role of temperature and particle size for nanofluid (A12O3) thermal conductivity enhancement," Appl. Phys. Lett., vol. 87, no. 15, p. 153107, Oct. 2005.

[56] A. Ahmadi Nadooshan, "An experimental correlation approach for predicting thermal conductivity of water-EG based nanofluids of zinc oxide," Phys. E Low-dimensional Syst. Nanostructures, vol. 87, pp. 15-19, Mar. 2017.

[57] M. H. Mirbagheri, M. Akbari, and B. Mehmandoust, "Proposing a new experimental correlation for thermal conductivity of nanofluids containing of functionalized multiwalled carbon nanotubes suspended in a binary base fluid," Int. Commun. Heat Mass Transf., vol. 98, pp. 216-222, Nov. 2018.

[58] Y. Li, M. Firouzi, A. Karimipour, and M. Afrand, "Effect of an inclined partition with constant thermal conductivity on natural convection and entropy generation of a nanofluid under magnetic field inside an inclined enclosure: Applicable for electronic cooling," Adv. Powder Technol., vol. 31, no. 2, pp. 645-657, 2020.

[59] Z. Chen et al., "A new correlation for predicting the thermal conductivity of liquid refrigerants," J. Therm. Anal. Calorim., pp. 1-6, 2020. 
[60] A. Akhgar and D. Toghraie, "An experimental study on the stability and thermal conductivity of water-ethylene glycol/TiO2-MWCNTs hybrid nanofluid: Developing a new correlation," Powder Technol., vol. 338, pp. 806-818, Oct. 2018.

[61] S. Sarkar and R. P. Selvam, "Molecular dynamics simulation of effective thermal conductivity and study of enhanced thermal transport mechanism in nanofluids," J. Appl. Phys., vol. 102, no. 7, p. 074302, Oct. 2007.

[62] A. Shahsavar and M. Bahiraei, "Experimental investigation and modeling of thermal conductivity and viscosity for non-Newtonian hybrid nanofluid containing coated CNT/Fe3O4 nanoparticles," Powder Technol., vol. 318, pp. 441-450, 2017.

[63] M. Ramezanizadeh and M. Alhuyi Nazari, "Modeling thermal conductivity of Ag/water nanofluid by applying a mathematical correlation and artificial neural network," Int. J. Low-Carbon Technol., vol. 14, no. 4, pp. 468-474, Nov. 2019.

[64] A. Ghasemi, M. Hassani, M. Goodarzi, M. Afrand, and S. Manafi, "Appraising influence of COOH-MWCNTs on thermal conductivity of antifreeze using curve fitting and neural network," Phys. A Stat. Mech. its Appl., vol. 514, pp. 36-45, Jan. 2019.

[65] Y. Xu et al., "Synthesis and characterization of additive graphene oxide nanoparticles dispersed in water: Experimental and theoretical viscosity prediction of non-Newtonian nanofluid," Math. Methods Appl. Sci., pp. 1-20, Apr. 2020.

[66] A. Moradikazerouni, A. Hajizadeh, M. R. Safaei, M. Afrand, H. Yarmand, and N. W. B. M. Zulkifli, "Assessment of thermal conductivity enhancement of nano-antifreeze containing single-walled carbon nanotubes: Optimal artificial neural network and curvefitting," Phys. A Stat. Mech. its Appl., vol. 521, pp. 138-145, May 2019.

[67] M. Afrand, M. Hemmat Esfe, E. Abedini, and H. Teimouri, "Predicting the effects of magnesium oxide nanoparticles and temperature on the thermal conductivity of water using artificial neural network and experimental data," Phys. E Low-dimensional Syst. Nanostructures, vol. 87, pp. 242-247, Mar. 2017. 